\title{
Da Biblioteconomia à Informática
}

\section{EVOLUÇÃO DO CONCEITO DE DOCUMENTAÇÃO}

\section{ABNER LELLIS CORREA VICENTINI*}

"O Homem cada vez sabe menos de tudo. Em compensação, tem cada vez mais possibilidade de saber tudo sôbre determinado assunto.

O Homem tem sido a medida de tôdas as coisas. Agora é o Computador que dá novas medidas a tudo" (274).

\section{BIBLIOTECONOMIA}

A Biblioteconomia surgiu como decorrência da necessidade de sistematização e organização das coleções de livros. Êstes constituíram os primeiros veículos de difusão dos conhecimentos humanos e de transmissão de cultura geral e especializada. O têrmo Biblioteca (do grego Biblion: livro, e theke: caixa) significa, etimològicamente, guarda ou custódia de livros (41). A história do livro e das bibliotecas (61) nos mostra que estas, na Antigüidade, constituíram privilégios reais e sacerdotais, como sucedeu com as grandes bibliotecas de Nínive e Alexandria. $\mathrm{Na}$ Idade Média as bibliotecas pertenceram quase que exclusivamente aos conventos (verdadeiros centros de difusão da cultura na época, como por exemplo o de Fulda, na Alemanha) e aos senhores feudais, continuando a ser privilégio dos eruditos e da nobreza. Sòmente na Idade Moderna, com o aparecimento da imprensa, com o barateamento dos livros, com a multiplicação de bibliotecas e sua inclusão nos planos nacionais de educação e de desenvolvimento, e ainda, com o rompimento das barreiras entre o livro e seu utilizador, pelo acesso livre às estantes e pelo empréstimo domiciliar, pôde a Biblioteca, finalmente, transformar-se em instituição democrática e afirmar-se como universidade do povo (241). A Biblioteconomia ditou as normas para a organização científica das bibliotecas, constituindo-se em verda-

* Conselheiro da FID e Membro de suas Comissões FID/CCC e FID/CR. Consultor da FAO para Documentação (Projeto FAO/UNDP-80/IICA: CERDAC), Turrialba, Costa Rica, América Central (abril/agôsto, 1970). Assessor para Documentação do Estado-Maior da Aeronáutica (EMAER), Ministério da Aeronáutica, Brasília, DF, Brasil. 
deiro complexo de técnica e ciência (244). Escolas de Biblioteconomia foram fundadas, cursos de nivel superior foram introduzidos, e bibliotecários foram diplomados, com o objetivo precípuo de cuidar das coleções de livros. Êstes, no entanto, em virtude das novas especializações (237) que surgiram em todos os ramos do conhecimento, se bem que alguns autores considerem a explosão do conhecimento como um mito (40), e que sòmente a explosão documental é realidade $(167,198,343,353)$, deixaram de ser os veículos exclusivos de transmissão da cultura. Segundo Lasso de la Vega (184) ao lado da falta de livros, preocupação do Renascimento, aparece outra preocupação maior no Século XIX: o excesso de produção livresca (198). Além do aumento de livros, surgiram novos periódicos em todos setores, as pesquisas passaram a ser publicadas em forma de relatórios, os anais dos congressos nacionais e internacionais tornaram-se mais volumosos com a proliferação das "comunicações" e dos "informes", as peças de laboratório se multiplicaram, e os filmes passaram a fazer parte do material educacional. Daí Ortega y Gasset (248) afirmar que o homem em vez de estudar para viver, passou a viver para estudar.

Tornou-se impossível ao especialista, ao pesquisador, ao cientista, acompanhar a literatura referente a sua especialidade.

Esta afirmativa pode ser comprovada pelo seguinte quadro estatístico que apareceu em publicação recente (114): se um químico, fluente em 30 línguas, começasse a ler em 10 de janeiro todos os documentos de seu campo de interêsse, durante 40 horas por semana, numa média de 4 artigos por hora, a 31 de dezembro não teria lido mais do que $1 / 10$ de todo o material publicado durante o ano, com a agravante de que não the teria sobrado tempo para aplicar o conhecimento adquirido. Conseqüentemente tôdas as ciências do universo entraram em fase de desenvolvimento e progresso. Lasso de la Vega, em seu último livro (186), historiando êsses progressos, afirma que da simples capacidade de visão do homem da época de Péricles chegouse ao microscópio eletrônico, o que permitiu examinar os centésimos milésimos de milímetro; a medição do ano luz, equivalente a dez mil milhões de quilômetros, se tornou possivel; outro tanto sucedeu em relação ao tempo, conseguindo-se observar fenômenos sucessivos a mil milionésimos de segundo, como ocorre com a excitação de um átomo por raios catódicos da emissão de raios X; no campo da energia, o cossmotrón criou raios que alcançam os seus milhões de volts-eletrônicos; em matéria de temperatura, partindo-se da simples diferença entre verão e inverno, passou-se do zero absoluto às centenas de miIhões de graus das radiações termonucleares .... E conclui 0 
ilustre bibliotecário espanhol: "Desta situação criada pelo homem chega-se à uma compreensão mais clara de sua posição no cosmos, de seus deveres no sentido de descobrir tôdas as leis que regem o universo e sua divina harmonia, e de seus esforços para dominá-las e colocá-las a seu serviço, convertendo-se em construtor do seu próprio bem estar. Assim o homem vem confirmando sua missão de pesquisador, dedicando-se à investigação de base ou fundamental, à aplicada ou técnica, e à operante ou social, que constitui a origem das inumeráveis conquistas que hoje desfruta".

Assim, da eletrotécnica surgiu a eletrônica, da física nasceu a atomística, a aeronáutica possibilitou o aparecimento da astronáutica, inaugurando-se a era dos satélites, foguetes balísticos e teleguiados. Como decorrência dos progressos da Biblioteconomia, em função dos progressos das demais ciências, vamos encontrar no século $X X$ a Documentação, e como evolução desta a Informática.

\section{DOCUMENTAÇÃO}

A palavra Documentação originou-se de "documento" (do latim: documentum = docere $=$ ensinar, portanto, aquilo que ensina, aquilo que transmite), e sua etimologia e significação foram estudadas por Arntz, atual Vice-Presidente da FID, em brilhante trabalho intitulado "Documentatio a documento" (10). Segundo Coblans (50) é impossível definí-la com exatidão, pois seu significado difere de país para país. Bradford (34) afirma que Documentação é a "arte de colecionar, classificar e tornar imediatamente acessível os registros de todos os tipos de atividades intelectuais". Para Shera (312) a "Documentação é uma parte do conceito de organização bibliográfica, definida como tendo por finalidade a canalização dos registros gráficos do conhecimento para seus usuários, para tôdas as finalidades e em todos os níveis do saber, de modo a tornar máxima a utilização social de todos os registros das experiências humanas". Diz ainda: "a Documentação limita-se ao mundo dos humanistas e cientistas e o seu objetivo é aproximar tôdas as atividades intelectuais que se utilizam de registros gráficos dos conhecimentos e todos os serviços intermediários que transmitem o material registrado do estudioso-produtor ao estudioso-consumidor" (313). Neal Harlow (134), ex-Diretor da Escola de Biblioteconomia da Rutgers University, em trabalho apresentado a uma reunião da CLA, assim se expressa: "A palavra Documentação com a qual podemos estar pouco familiarizados no sentido em que é usada hoje em dia, é um têrmo geral e compreensivo, como bibliografia e comunicação. Está intimamente ligado à 
Biblioteconomia, e pode, na verdade, ser incluído na mesma família de que a Biblioteconomia é membro". Para Briet (35) o "material da Documentação consiste de todos os índices concretos ou simbólicos, conservados ou registrados de nôvo, de modo a apresentar, reconstituir ou provar um fenômeno físico ou intelectual". Ditmas (70) ex-Presidente da ASLIB (144) situa a Documentação como "o setor da bibliografia em que a principal preocupação é o aperfeiçoamento dos meios para a utilização ativa dos registros do conhecimento humano, em oposição à sua guarda". Malclés (207/210), entre outros, considera a Documentografia como ciência geral do documento, separando-a e opondo-a à Bibliografia, e classifica os documentos em quatro grupos principais:

1) Documentos gráficos, que incluem os manuscritos e impressos. Os primeiros são estudados pela Paleografia e são conservados em arquivos; os segundos, por outro lado, constituídos de textos tipográficos, pertencem exclusivamente ao domínio da Bibliografia.

2) Documentos iconográficos, constituídos pelos retratos, desenhos, gravações, fotografias, plantas, cartas geográficas, ilustrações, quadros etc.

3) Documentos plásticos: selos, moedas, medalhas e todos os objetos originados do trabalho em relêvo de metal, gêsso e plásticos em geral.

4) Documentos fônicos: discos, fitas magnéticas etc.

E conclui: A Documentografia-tronco comum do qual derivam tôdas as espécies de documentos - é o gênero, vale dizer, a ciência teórica de caráter geral, e se aplica ao estudo dos documentos iconográficos, plásticos e fônicos. A Bibliografia, por sua vez - documentografia especial - estuda ùnicamente os documentos gráficos.

A palavra Documentação foi criada por Paul Otlet (249/252) para designar a ciência e as técnicas gerais do documento. Emprestou ao vocábulo documento um sentido mais amplo que ao têrmo livro, afirmando no discurso de abertura do Congresso Mundial de Documentação de 1937, que o mesmo compreende não só os textos manuscritos ou impressos, qualquer que seja sua forma, assim como todos os sinais visuais e auditivos etc., suscetíveis de transmitir uma informação: discos, gravuras, mapas, fotografias, selos, medalhas, filmes etc. Otlet identifica a Documentação com a Bibliologia, fazendo dela uma disciplina geral de conteúdo vastíssimo, pois, segundo sua concepção, a mesma abrange o conjunto sistematizado dos conhecimentos 
relativos à produção, conservação, circulação e utilização dos escritos e documentos de tôdas as espécies. Divide a Documentação ou Bibliologia em quatro grupos:

1) Bibliologia lógica, que trata das relações do livro com a exposição da ciência.

2) Bibliologia psicológica, que se refere às relações do livro com o autor.

3) Bibliologia tecnológica, que estuda as relações do livro com os meios materiais de sua fabricação e difusão.

4) Bibliologia sociológica, que compreende as relações do livro com a comunidade em cujo ambiente nasce e para o qual está destinado.

De outro ponto de vista considera a Documentação sob três aspectos: a) como ciência e doutrina; b) como técnica; c) como corpo sistematizado de organização. Como ciência a Bibliologia tem por objeto a descrição histórica dos documentos e seu estudo comparativo (Bibliografia), e a teoria geral dos mesmos. Como técnica estuda as regras para produção, circulação, conservação e utilização dos documentos. Como organização se refere ao arranjo racional do trabalho individual e coletivo para facilitar o aproveitamento dos materiais com o máximo de economia (41).

Moller (235) declarou que "uma das tarefas mais importantes da Documentação é oferecer uma visão panorâmica dos progressos do saber humano, tornando mais fácil o encontro do material necessário, tanto para os cientistas como também para os interessados em economia e técnica".

Segundo Taube (334), Documentação é "um complexo de atividades necessárias à comunicação de informações especializadas, incluindo a preparação, a coleção, a análise, a organização e a distribuição dos registros gráficos do conhecimento humano".

Balbis $(18,19)$ na Itália, Schürmeyer (293 na República Federal da Alemanha, Koblitz (175) na República Democrática Alemã, Majewski (205) na Polônia, Ranganathan (271, 272, 273) na índia, Tell $(340,341)$ na Escandinávia, Laclemandière (182) na França, Polushkin (267) na União Soviética, Loosjes (200) e Donker Duyvis (72) na Holanda, Lasso de la Vega (185) na Espanha, e muitos outros nos diversos países também discutiram o assunto e a delimitação (308) do campo da Documentação (170), dando suas interpretações e definições (63).

Após o exame das definições elencadas conclui-se que, apesar das divergências, os autores são acordes ao afirmar 
que a Documentação se preocupa também com o material "não livro", dando uma acepção bem ampla ao têrmo "documento" (163), que compreende tudo o que pode transmitir o conhecimento humano: livros, revistas, artigos de periódicos, filmes, microfilmes, microfichas, fotografias, microfotografias, lâminas, transparências, diapositivos, desenhos, mapas, relatórios, especificações, normas técnicas, patentes, fitas gravadas, discos, partituras, diafilmes, cartões perfurados, fotocópias, manuscritos, selos, medalhas, quadros, amostras, espécimes, modelos, fac-similes etc., e; de maneira geral, tudo o que tenha caráter representativo a três dimensões e, eventualmente, em movimento, porém, submetido à intervenção de uma inteligência ordenadora.

\section{BIBLIOTECONOMIA vs. DOCUMENTAÇĀO}

O problema "Biblioteconomia versus Documentação", que já focalizamos em outro estudo (357), dominou por muito tempo o panorama internacional e foi tema comum nas publicações especializadas. Tendo como base o raciocínio seguido por Shaw (304), e depois de uma análise comparativa dos debates nos países socialistas (236) e das opiniões emitidas por Kent (165), Dembowska (66), Kunze $(180,181)$, Fill (106), Fry (117), Mohrhardt (234), Harlow (134), Shera (310, 313, 315), King (170), Coates (49), Kevérgant e Fourmont (166), Taube (335), Ashworth (15), Verhoef (356) e Lasso de la Vega (183), inter alia, podemos chegar a uma visão panorâmica das relações entre as duas ciências. Imaginemos um ciclo completo de informações que compreenda: identificação, localização, encontro, transformação em forma mais prática para utilização, síntese e disseminação do conteúdo intelectual. A Biblioteconomia se ocupa da fase que vai do registro ao encontro do material, e usa para tanto a seleção de livros, a catalogação, a classificação e a bibliografia. A Documentação se encarrega da identificação, da transformação, da síntese e da disseminação, e para tanto, emprega a seleção, a reprografia $(58,86,92,113,158,266)$, a fotografia, a indexação, a bibliografia, a recuperação etc.

A controvérsia entre os autores chegou a tal ponto que Rost (280), compilou uma bibliografia sôbre o assunto, e a IFLA dedicou uma de suas reuniões anuais, a $32^{\mathrm{a}}$ de 1966, em Haia, à discussão do tema (26). O ponto de vista americano foi expresso por Mohrhardt, o da Europa Ocidental por Libaers, e 0 da Europa Oriental por Kondakov (189). Dando suas impressões sôbre esta reunião, Loosjes (199), então Presidente da IAALD, concluiu que há uma grande área de superposição entre ambas, sugerindo a criação de um nôvo nome para a "amalga- 
mation" das duas ciências. Para resumir a controvérsia citaremos mais uma vez Loosjes (200) que classifica as definições resultantes da comparação "Biblioteconomia vs. Documentação", em quatro grupos: 1) Definições englobativas, ou de Superposição, que descrevem os objetivos da Documentação de forma tão exaustiva que incluem a totalidade da Biblioteconomia. Tudo está estruturado como função da documentação, desde a aquisição, o arranjo e a explotação de documentos, inclusive o trabalho do editor. Aqui estão incluídas as definições de Otlet, da FID, de Frank, de Briet, e a de Shera, quando fala de "organização bibliográfica". 2) Definições paralelas, ou de Justaposição, que colocam a Biblioteconomia e a Documentação em posição paralela uma a outra. Estas incluam as definições de Pietsch (263/265), segundo o qual o bibliotecário "guarda" a coleção enquanto o documentalista "explota-a", de Fill (106), de Reeser, de Shera, de Coblans etc. 3) Definições de subordinação, ou de Infraposição, que englobam as idéias de Kunze $(180,181)$, de Bjorkbom (29), e de todos os bibliotecários tradicionalistas. 4) Definições que não estabelecem ligação entre as duas ciências, ou de Desconexão, representadas pelas opiniões de Picard, Scotecci (265), Riemsdijk, e outros documentalistas radicais. Em nossa opinião a diferenciação entre Documentação, Biblioteconomia e Bibliografia especializada é, antes de tudo, uma questão de gradação. Os campos estão intimamente ligados, e uma pessoa pode, quase que simultâneamente, mas não de forma total, desempenhar funções nos três campos. As atividades biblioteconômicas, tais como, aquisição, catalogação, circulação (que constituem parte, mas não significam a totalidade do trabalho) são pré-requisitos da Documentação. Assim também a bibliografia é òbviamente pré-requisito para uma análise intensiva do conteúdo intelectual. O bibliotecário inicia a análise do assunto nos processos de catalogação e classificação, e quando passa para o estudo intensivo das idéias contidas em cada item de cada fonte, êle passa para a função de documentalista. De acôrdo com êste pensamento, Shera (310) afirma que a Documentação não sugere uma nova ciência para suprimir os bibliotecários, mas, antes de tudo, representa um moderno ponto de vista, novos aspectos de uma antiga e respeitada profissão; e o documentalista procura, não o descrédito do bibliotecário, mas dar-lhe novos auxílios e métodos modernos com os quais ampliará o seu valor social, habilitando-o a uma maior contribuição intelectual. E vai mais além o diretor da Escola de Biblioteconomia da CWRV, expondo sua filosofia da biblioteconomia e da documentação (307) e especificando que a transformação da Biblioteconomia (pela inclusão de cursos de documentação 
nos currículos das escolas tradicionais) não foi uma rejeição às tradições da ciência biblioteconômica, mas um desenvolvimento lógico da profissão para atender às novas necessidades. Isto não significou voltar as costas à Biblioteconomia que vinha sendo praticada há longo tempo, mas sobretudo, uma reafirmação de fé na capacidade do bibliotecário em prestar à coletividade novos serviços além dos que já oferecia. Os significativos progressos científicos, particularmente no campo da eletrônica, passaram a exigir e a requerer, nas expressões de Clapp (48), Graziano (128), Wasserman (368), Sir Francis Frank (112), e Waldron (366) um reexame e uma nova ênfase na filosofia e nos princípios básicos da Biblioteconomia. Coblans (50) acredita firmemente que a separação entre a Biblioteconomia e a Documentação é um retrocesso, que convém evitar, declarando, outrossim, que o bibliotecário e o documentalista devem ser especializações de uma mesma profissão. A Documentação trouxe uma nova mentalidade que forçou gradativamente a extensão dos limites da biblioteconomia tradicional e se incluiu em suas práticas. A Documentação constitui-se, portanto, em verdadeira especialização da Biblioteconomia que se originou do desenvolvimento acelerado do serviço de referência, motivado pela necessidade de se encontrar, tratar e selecionar, de modo cada vez mais ràpido, dinâmico (358), fácil, uniforme e sistematizado, tôdas as formas de material bibliográfico, ou seja, de "documentos", colocando-as à disposição dos usuários $(253,290,350)$.

\section{ORGANIZAÇÃO DA DOCUMENTAÇÃO}

$O$ organismo internacional mais ativo no vasto campo da Documentação é a FID (296). De acôrdo com seu Anuário para 1970 (103), a FID congrega 53 países, sendo 22 da Europa, 12 das Américas, 13 da Asia e Oceânia, e 6 da África, tendo em cada um dêsses países um organismo que é o membro nacional, mais 126 membros institucionais e 115 membros individuais. A Federação conta com 2 Comissões Regionais, uma para a América Latina (FID/CLA) (118), fundada em 1960, no Rio de Janeiro, por ocasião da 26a Conferência Geral da FID, sob a inspiração de Lydia de Queiroz Sambaquy (286), ex-vice-presidente da FID, fundadora do IBBD (145), uma "bandeirante" (361) da biblioteconomia e da documentação na América Latina, eleita "membro honorário" da FID em 1969 (90, 287). A FID/CLA tem 10 membros nacionais, já realizou 9 reuniões gerais e 2 congressos regionais de documentação (10 no México em 1967, e 2 ? no Rio de Janeiro em $1969(56,57)$. A outra Comissão Regional, destinada à Ásia e Oceânia, foi fundada em Tóquio, no ensejo da 33 a Conferência Geral, contando com 13 membros na- 
cionais, reunindo-se pela primeira vez em abril de 1970 (104). A FID realizou em Buenos Aires, de 14 a 22 de setembro de 1970 sua 35 a Conferência-Geral $(87,378)$.

A FID foi fundada em 1895, evoluindo de IIB para IID, e finalmente para Federação a partir de 1937. Sua história pode ser dividida em quatro períodos marcantes, a saber: 10) Período Otlet/La Fontaine 1, de 1895 a 1928, que marcou o lançamento da instituição, pelos seus planos de organização de um catálogo mundial destinado a cobrir a produção bibliográfica de forma total, e pela criação da Classificação Decimal Universal (CDU); 29) Período Donker Duyvis², (352), de 1929 a 1959, que se concentrou na expansão e aprimoramento da CDU, pelo aparecimento de suas edições em línguas orientais; por fixar a diferenciação entre Biblioteconomia, Bibliografia especializada e Documentação, e ainda pela preocupação inicial com os problemas de foto-reprodução; 39) Período Voorhoeve/Van der Brugghen $^{3}$, que contou com as presidências de King e Lowry, iniciado em 1959 com a aprovação em Varsóvia (25a Conferência Geral da FID) do "Programa a Longo Prazo" (96), projetou a FID na América Latina, ampliou o número de comissões técnicas, instalou o departamento de classificação, e reformulou a comissão dedicada aos estudos de formação e preparação de documentalistas; e 4\%) Período Sviridov ${ }^{4}$ (325/329), que contou com a presidência de Lowry e agora de McBurney, iniciado em 1966, que vem se caracterizando pela reformulação do plano de ação da FID face ao impacto de Revolução da Informação e da Automação, tendo como conseqüência a criação de uma nova comissão dedicada a Pesquisas sôbre as bases teóricas da informação" (FID/RI), à reorganização da comissão de estudos sôbre mecanização, armazenamento e recuperação de informações, em duas outras, sendo uma dedicada à teoria das máquinas e sistemas (FID/TM), e outra às técnicas operacionais das máquinas (FID/OM), com a promoção de congressos nesse campo (88); reconstituição das comissões envolvidas com os problemas de lingüística na documentação (FID/LP), e informação para a indústria (FID/II); pela instalação de uma comissão para a problemática da documentação nos países em fase de

1. Paul Otlet e Henry La Fontaine, belgas, foram os fundadores da FID.

2. F. Donker Duyvis, holandês, foi Secretário-Geral até 1959.

3. Willem van der Brugghen, holandês, foi Secretário-Geral Interino de 1963 a 1966, tendo completado em 1969 vinte anos consecutivos de serviços prestados à FID, exercendo atualmente a chefia dos serviços de informação e publicação da FID. N.A.J. Voorhoeve, holandês, foi Secretário-Geral Interino de 1959 a 1961.

4. Felix A. Sviridov, russo, é o Secretário-Geral desde 1966. 
desenvolvimento (FID/DC) (105); e também por dar uma nova projeção à Classificação Decimal Universal, por iniciativa de Lloyd $(196,197)$ através de estudos realizados pela Comissão Central de Classificação (FID/CCC) e pela Comissão de Pesquisas em Classificação (FID/CR) para utilização da CDU em sistemas mecanizados de recuperação de informações ${ }^{5}$ (97), com a divulgação dos trabalhos e experiências levados a efeito por Rigby (279), Caless (43), Freeman e Atherton (115), Nystrom (246), Perreault $(260,262)$, e Vicentini e Oliveira (363). O ponto alto dêste período tem sido o patrocínio de vários projetos de âmbito internacional $(171,326)$.

\section{SUBSTÂNCIA DA DOCUMENTAÇÃO}

De acôrdo com a doutrina clássica da FID "Documenter c'est réunir, classer et distibuer les documents de tout genre dans tous les domaines de l'activité humaine". Essa conceituação, que constituiu por muitos anos o "leif motiv" da FID, foi, no entanto, alterada no nôvo programa da Federação para "Documentação é a coleção, armazenagem, classificação, seleção, disseminação e utilização de tôda a informação". Assim, a unidade documentária, ou seja a substância da documentação deixou de ser o documento pròpriamente dito, vindo a ser a informação em si mesma. A FID passou, então, a preocupar-se dentro do seu programa a longo prazo $(12,96,101,329)$ com a média de crescimento da produção da informação $(322,353)$, com os problemas de avaliação da informação (8), com a evolução dos meios de transmissão da informação $(216,343)$, com a organização e compatibilidade dos sistemas de informação (243), com o tratamento lingüístico da informação $(67,135,201,319)$, e, sobretudo, com o fator humano envolvido nas atividades de informação, tanto com o transmissor, como com o receptor da informação, o usuário $(253,290,350)$. Em fim, com a "crise da informação" $(9,275)$. Tendo em vista as tendências atuais da Documentação como decorrência do advento dos computadores e ordenadores, que já estão na 4ạ geração (159), o Conselho da FID está estudando em $1976{ }^{6}$ um nôvo Programa $(94,98)$ para, com estruturas verdadeiramente científicas: 1) definir novas linhas orientadoras na consecução das metas e objetivos constantes dos estudos (102); 2) elaborar nova metodologia para pesquisar as bases teóricas da informação científica; 3) dar as-

5. O 10 Seminário sôbre o emprêgo da CDU em sistemas mecanizados de recuperação de informações foi realizado em Copenhagen, setembro, 1/6, 1968. O 2 foi realizado em Frankfurt/Main, junho, 1/5, 1970.

6. O nôvo programa foi aprovado pela Assembléia-Geral realizada por ocasião da 35a Conferência da FID, em Buenos Aires, setembro, 14/24, 1970. 
sistência necessária ao estudo dos meios e métodos convencionais e não-convencionais da disseminação da informação, abrangendo tanto as publicações primárias como secundárias e a armazenagem e recuperação mecanizada de informações, e incentivar o estudo de linguagem para ordenadores $(140,156,370)$; 4) avaliar os sistemas de informação nacionais, regionais e internacionais (271) colaborando nesse último campo com a UNESCO e a ICSU no projeto UNISIST $(11,270$, $349)$; 5) desenvolver a CDU para atualizá-la e adaptá-la a um sistema internacional unificado para indexação de documentos cientificos; 6) tomar medidas tendentes a resolver o problema da "barreira lingüística" no escoamento da informação (62), 7) propiciar e aperfeiçoar o treinamento de pessoal encarregado, tanto da disseminação, com o da utilização de informação; 8) revitalizar as atividades internas, como o estabelecimento de prioridades específicas; 9) auspiciar projetos internacionais cooperativos (326), e, ainda, 10) organizar, sob os auspícios da UNESCO, o "Ano Internacional da Informação Científica e Técnica em 1974".

A FID, pois, na sua programação, tanto na vigente, como na prospectiva, se ocupa, primordialmente, da "Informação" $(1,31,33,59,116,123,203,222)$.

\section{INFORMAÇÃO}

O têrmo Documentação sofre, portanto, e à sua vez, uma evolução semântica e começa a ser substituído por informação. Vannevar Bush (42) logo após o término da 2a Grande Guerra, em virtude do seu famoso artigo "As we think", pode ser considerado como o "pai da ciência da informação", em decorrência da apresentação do seu sistema "Memex" (75). Surge assim, entre outras (237), uma nova Ciência. Donohue e Karioth (75) nos fornecem a certidão de nascimento da criança, que segundo Berry (27) ficou algum tempo sem nome, e agora atende por vários dêles. Afirma que, apesar das divergências quanto ao nome, se trata de uma nova Ciência. Citando Hoselitz (143) estipula três condições para o aparecimento de uma nova disciplina: 1) Problemas - existência de problemas para atrair o pesquisador; 2) Generalizações - coleção de dados suficientes para permitir a promulgação de generalizações; 3) Reconhecimento - que se evidencia pelo surgimento de instituições devotadas ao nôvo setor e consagração acadêmica. Segundo Donohue e Karioth, já citados, a ciência da informação preenche todos êsses três requisitos e ainda outros três mais, a saber: complexidade, adequação à sua estrutura educacional e livre escoamento de idéias. Taylor (339) define a nova ciência como 
"o estudo das propriedades, do comportamento e do escoamento da informação", afirmando que ela abrange: 1) todos os aspectos afins da informação-comunicação; 2) análise da linguagem e da informação; 3) a organização da informação, e 4) as relações homem-sistema. Passa-se, portanto, ao estudo da informação científica, e de sua contribuição para a organização da ciência $(263,282,365,373)$, motivando-se, assim, o aparecimento de uma literatura tão vasta que Neeland (240) e Speer (323), em bibliografias recentes sôbre a ciência da informação, chegam a registrar 1.924 e 3.079 referências respectivamente. Inicia-se, assim, a era da computação da informação $(25,51,52)$, de redefinições de conceituação (164), de luta do tradicionalismo contra as inovações (73), e do estabelecimento de novos padrões para as bibliotecas e centros de documentação e informação do futuro $(22,48,83,192,194,303,314,354)$.

As conclusões da "Conferência Internacional sôbre Informação Científica" (157) realizada em Washington, D.C., em 1958, serviram de base para determinar as etapas do desenvolvimento futuro e dos progressos da documentação $(24,60,83,110,192$, $214,303,314)$ da caracterização da informação científica (75, $222,274)$, da mecanização (515) e da automação $(3,25,224$, $288,300,362$ ) e forneceram os elementos para programar a definição da nova problemática neste setor (324). Foi o ponto de partida da explosão $(167,253)$ e da revolução $(2,221,367)$ da informação, da automação e da telecomunicação já mencionadas nos períodos da história da FID, que afetadas também pela cibernética $(232,340)$ atingiram, conseqüentemente, os métodos de processos de comunicação $(3,39,79,281,364)$ técnico-científica $(254,294)$, estabelecendo novas inter-relações $(68,120$, 217).

A introdução da palavra Informação começa a ganhar terreno, alterando não só os objetivos das instituições, mas até mesmo os títulos de publicações periódicas e o nome das entidades em diversos países. Foi o caso do "American Institute of Documentation" (ADI), hoje "American Society for Information Science" (ASIS) (80), do "Library Science Abstracts", agora "Library \& Information Science Abstracts (LISA) (78, 190), e do "Documentation Abstracts", desde 1969 "Information Science Abstracts" (ISA) (154), para citar apenas três casos. Uma visão panorâmica da evolução dos serviços de informação científica nos Estados Unidos foi apresentada por Marietta Daniels Shepard $(305,306)$.

O passo seguinte da nova revolução foi atingir os programas educacionais para formação de bibliotecários e documen- 
talistas, e iniciar a preparação de engenheiros e cientistas da informação $(32,53,77,82,136,137,138,193,206,238,276,292$, 297, 318).

A FID patrocinou em 1967, em Londres, uma conferência internacional sôbre "Education for Scientific Information Work" (93), e nos Estados Unidos foi realizado um "Symposium on Education for Information Science" (332). A FID publicou também um diretório/guia internacional das instituições que proporcionam treinamento para o trabalho de documentação e informação (89).

Como conseqüência a Informação foi definitivamente incorporada aos novos currículos $(53,84,85,369)$ uma vez que a formação profissional, convencional e tradicional, deixou de atender às necessidades atuais, segundo, entre outros, Klempner (172), Swank (330), Winger (371), e Sabor (283), em sua recente metodologia do ensino da biblioteconomia publicada pela UNESCO, e ainda de acôrdo com os padrões estabelecidos pelo ADI (4). De acôrdo com as considerações de Hayes (136/139) e as estatísticas compiladas por Schick (291) e pela AALS (69) trinta e cinco das 50 escolas acreditadas em $1970^{7}$ pela ALA (5), dão pelo menos um curso sôbre "Ciência da Informação e Sistemas" (em 1967 eram apenas 25), e vinte e sete ministram a disciplina "Automação de Bibliotecas e Processamento de Dados". Algumas universidades dão mais de um curso, como por exemplo UCLA e Chicago, seis cursos cada; nove a Universidade da California (Berkeley); treze a CWRU. Além disso, doze escolas ainda não reconhecidas oferecem também êsses cursos. Algumas escolas chegaram até a incluir em seus próprios nomes a palavra Informação, como é o caso das Universidades de Pittsburgh, Maryland, Missouri, Columbia, Brigham Young, Western Ontario e Pratt Institute (5).

Segundo Rees (276) os cursos podem ser englobados em três categorias diferentes: 1) Automação de Bibliotecas, que inclui a análise dos sistemas, ordenadores, computadores e equipamento periférico, teoria e prática da automação das operações e técnicas biblioteconômicas com relação à aquisição, publicações periódicas, catalogação, circulação etc.; 2) Sistemas de Armazenagem e Recuperação de Informações, que engloba o estudo dos sistemas de recuperação, de análises de conteúdo, preparação de resumos analíticos e indexação, estruturas dos idiomas para indexação e elaboração de "thesaurus", arranjo de catálogos, análise de pesquisas, estrategia

7. Edição de fevereiro de 1970 . A próxima revisão sairá em novembro de 1970 . 
de localização, tradução e disseminação, e reprografia; 3) Metodologia da pesquisa em ciência da informação, que abrange os princípios e instrumentos básicos da matemática, da lógica, da lingüística, da estatística, da psicologia, e de outras disciplinas, e de suas aplicações ao estudo das atividades biblioteconômicas vinculadas com a comunicação.

Em 1967, o número de cursos em relação a essas três categorias, era o seguinte: 1a Categoria, 25 cursos em 17 universidades; 2a Categoria, 39 cursos em 17 universidades; 3 a Categoria, 13 cursos em 6 escolas.

7. INFORMAÇÃO \& DOCUMENTAÇÃO \& BIBLIOTECONOMIA

$\mathrm{O}$ antigo problema "Biblioteconomia vs. Documentação" se transforma em "Documentação e Informação", passando ainda para uma nova dimensão "Biblioteconomia e/ou/vs. Informação científica".

Da mesma forma que o tema anterior, a nova facêta vem sendo discutida e focalizada nas revistas e congressos dedicados ao assunto. Além do aparecimento de uma enciclopédia, editada por Kent, Lancour e Nasri (81), Barth (21), Saracevic (289), Foskett (109), Farradane (83), Beyssac (28), Grose (129), Lethève (188), Murdock (239), Hayes (139), Taylor (337/338). Donohue (que procura estabelecer as relações lógicas e epistemológicas das duas ciências com a teoria do conhecimento (74, 75), Fonotov (108), Koblitz (174/177), Ranganathan (275), Mironescu (233), Shera (316), Ashworth (14), Mumford (238) e Pietsch (263), vêm estudando o problema e concluem que a Informação passou a exercer uma influência decisiva e capital nas bibliotecas e centros de documentação e nas profissões a êles relacionados. Para comprovar esta afirmativa vamos encontrar as recentes atividades dos organismos internacionais $(153,387)$. A UNESCO ampliando seus objetivos e finalidades $(46,64)$, transformou sua antiga Divisão de Bibliotecas em Departamento de Documentação, Bibliotecas e Arquivos, com vasto programa de ação $(230,346)$, promovendo a instalação de centros nacionais de documentação (345), publicando guias mundiais de serviços de informação em ciência e tecnologia ( 347 , 348), e estabelecendo um grupo de trabalho para estudar um sistema mundial de informação científica $(270,325)$. A ICSU e a FID também estão envolvidas neste projeto de rêde internacional. A IFLA (296) dedicou sessões especiais ao tema "Automação das Bibliotecas" nas suas reuniões anuais de 1968, 34a, em Frankfurt $(119,127)$, e de 1969, 35a, em Copenhagen. O impacto do computador $(13,125,311,320,322,344,356)$ nas atividades do bibliotecário (107) e na profissão como tal (191), 
assumiu tamanha importância que entidades norte-americanas e britânicas convocaram uma conferência especial para discutir a influência dos computadores nas bibliotecas (168), a "AngloAmerican Conference on the Mechanization of Libraries" (55, 213). Além da preocupação com o planejamento e o financiamento $(195,257,258,299)$ dos serviços de documentação e informação, entidades e associações de classe começam a incentivar a criação de rêdes e programas cooperativos de informação (256), e passam a incluir, nas suas estruturas, departamentos especializados para tratar dos problemas da Informação. Êste foi o caso da ALA, que apesar de nunca ter usado a palavra documentação criou, a partir de 1967 , uma nova área de serviço em sua organização interna, a "Information Science and Automation Division" (288). A Biblioteca Nacional "Lenine", da União Soviética, reformulou seu organograma funcional para incluir um nôvo "Departamento de Mecanização e Automação da Biblioteca e dos Processos Bibliográficos" (242).

Na América Latina o IICA (212), coadjuvado pela AIBDA (255) (com seu programa BAL), exerce uma posição de liderança no estabelecimento de uma rêde de informação científica no campo da agricultura e das ciências afins, com planos de "projeção hemisférica" para se transformar em "Organização Interamericana de Agricultura" (7), e criação de um centro de informática agrícola em nível interamericano (CIDIA) e regional (CERDAC). O IICA, no entanto, se mantém em atitude alerta para uma verdadeira cooperação internacional (211) no que diz respeito ao emprêgo e à compatibilização dos sistemas automatizados de recuperação de informações (243). Essa compatibilização se refere, principalmente, aos projetos da NAL/ EUDUCOM $(160,316)$, INIS $(162,372)$, IFIS, UNISIST $(11,259$, $270,349)$ e do Centro de Documentação da FAO $(16,76)$, para o estabelecimento de um "world-wide-agricultural information system".

Convém aqui, a título de parêntesis, ressaltar a importância das rêdes de informação nacionais (360), regionais e internacionais, que, segundo McBurney (201), presidente atual da FID, vêm sendo relegadas a um plano secundário nos países democráticos, e altamente enfatizados nos países socialistas.

Várias publicações periódicas novas surgiram focalizando a automação das bibliotecas, entre elas "Information Storage and Retrieval", 1963, "Program: News of Computers in Libraries", 1966, "Information Retrieval and Library Automation", "Library Technology Reports", 1965, "The Information Scientist", 1967, "Journal of Library Automation", 1968 etc. 
A bibliografia sôbre automação das bibliotecas já é tão volumosa que a última compilação feita por Charlene Mason, para a "ERIC/CLIS", atingiu a 393 itens (215). Outras bibliografias cobrindo o assunto foram elaboradas por Bagley (17), Balz e Stanwood (20), Basset (23), Carlson (44), Cayless (4), Gates (121), Holzbauer (142), Kimber (169), Krikelas, (178, 179), McCune e Salmon (203), Neeland (240), Speer (323), Taylor (336), Swanson (331), e, ainda, aparecendo anualmente como seção especial do "Annual Review of Information Science and Technology" (6).

A documentação sôbre documentação e informação cresceu tanto que mereceu um estudo de Gilchrist (124) sôbre as inúmeras publicações periódicas que se ocupam dos serviços de resumos "abstracts", e "deppouillement" neste campo.

A informação, portanto, chegou, criou raízes, e se ramificou. Vários são os campos e os setores dentro da ciência da informação destinados a investigar as propriedades e o comporportamento da informação, as fôrças que regulam o escoamento da informação, e os meios de processamento e compatibilidade (243) da informação para torná-la acessivel a todos os usuários $(253,290,350)$. Para exemplificação bastaria citar a pesquisa e a análise crítica feitas, em nivel internacional, por Georgetta Lázárescu (187), de 128 sistemas mundiais não-convencionais de recuperação de informações.

Portanto, como ciência diz respeito ao conjunto de conhecimentos humanos relativos à produção, coleção, organização, armazenamento, recuperação, reprodução, utilização e comunicação da informação, e também à preparação de pessoal especializado para desempenhar tôdas essas funções. Essas funções, por sua vez, significam coisas diferentes nas diferentes regiões do globo. Para caracterizá-las surgiram os têrmos: Biblioteconomia, Bibliografia, Bibliologia $(41,236,249 / 252)$, Documentação, Documentologia (161), Documentografia (207/210), Documentalística (36), Ciência do Documento, Informação Científica, Ciência da Informação, Informatologia, Teoria da Informação, e agora INFORMÁTICA.

O pessoal especializado para desempenhar essas funções forma as categorias profissionais dos bibliotecários, bibliógrafos, documentalistas, cientistas da informação, oficiais de informação, especialistas em reprografia, indexadores etc., que são coadjuvados, no exercício de suas atividades, por matemáticos, programadores, economistas, comunicadores, estatísticos, engenheiros eletrônicos, educadores, planejadores, médicos, linguistas, etc., em verdadeiro intercâmbio de ciências e técnicas, tendendo à unificação do conhecimento. 


\section{INFORMÁTICA}

O índice anual do "Library Science Abstracts" (190) registrou pela primeira vez a entrada INFORMÁTICA em seu volume 18 , correspondente ao ano de 1967, remetendo para resumo $67 / 758$, que analisou o artigo de Mikailov, Chernyi e Gilyarwskii (225/229), publicado no periódico russo dedicado aos estudos de informação técnico-científica "Nauchno-Teknicheskaya Informatciya", Volume 12, 1966, páginas 35-39, com o título "Informática-nôvo nome para a teoria da informação científica" (227). Por ocasião da 33a Conferência Geral da FID, realizada em Tóquio, em setembro de 1967, o Prof. Mikhailov, diretor do VINITI, atual vice-presidente da FID, e presidente da comissão FID/RI, apresentou novo trabalho sob o título "Informática: uma disciplina científica" (223), defendendo a implantação do neologismo. Em 1968, novamente com seus colegas Chernyi e Gilyarewskii, divulgou nôvo trabalho sôbre "informatics, its scop and methods" (228), publicando, no mesmo ano, com os mesmos colaboradores, o primeiro livro, que ostenta a palavra Informática no título (226). Na França apareceu o periódico "01 Informatique" e - Annuaire Général de I'Informatique" (374).

Um dicionário foi publicado por Guilhaumou (130) em 1969, "Lexique de l'Informatique", e um outro, poliglota, deverá ser lançado pelo COMECON em fins de 1971 com o título "Terminologicesky Slovar'po informatike" (54). Sob os auspícios do VINITI, foi editado em 1968 estudos realizados pela FID/RI com o título "Teoreticeskie problemy informatiki" (Problemas teóricos da informática), traduzido para o inglês em 1969 (38,95). A FID e o VINITI divulgaram, em 2 volumes, os 65 trabalhos apresentados ao "Mezhdunarodnyi Forum po Informatike/International Forum on Informatics" (93). Nos anos de 1968 e 1969 apareceram ainda outros trabalhos teóricos sôbre informática, entre os quais citaremos os de: Mikhailov, Chernyi e Gilyareweskii (229) sôbre metodologia da informática; três de Merta $(218,219$, 220) estudando a definição da informática, suas ligações sociais com a transferência da informação, e incluindo-a como ramo da ciência; de Briskman (36) comparando bibliografia e documentalística, e fazendo sinonimia entre esta e informática; de Blek (30) criticando a teoria de Briskman e declarando ser a bibliografia parte da informática; de Szentmihályi (333) analisando as teorias de Mikhailov; de Cigárnik (47) focalizando o ensino da informática nos Estados Unidos da América; de Foskett (111) examinando os aspectos básicos da classificação como instrumentos da informática; de Novikov (245) discutindo os problemas psicológicos da informática; de Gyore (133) abordando a 
tipologia do usuário da informática, e as relações dêste com a teoria da comunicação; de Vadja (351) comentando as idéias de Pal Gyore para afirmar que na informática, além da personalidade humana, há outros elementos também importantes, sugerindo mudança das discussões teóricas e terminológicas para a pesquisa prática nesse setor; e ainda as contribuições apresentadas ao "Colloquium on Information Theory" (278), realizado em Budapest, editadas por A. Renyi, com recensão de B. C. Brookes (37), evidenciando as novas implicações da informática. A linha de afinidade dos 35 trabalhos independentes apresentados a êsse colóquio foi a aceitação da "Teoria da Informação de Shannon" como pedra angular do problema, e a sua conexão com a informática. Alguns trabalhos de aplicação da informática começaram a surgir, entre os quais, os de Delbor e Dumoit (65) na informática geológica, e de Hahn e Trabant (133) na informática catalográfica.

A partir de 1969 surgiram vários periódicos especializados em ciência da informação, e outros alteraram os seus títulos para INFORMÁTICA, como por exemplo:

1) Na Alemanha Oriental: ZIID-Zeitschift (Probleme der Information und Dokumentation in Wirtschaft und Wissenschaft), que se chamava antes "Dokumentation" e agora "Informatik" (147).

2) Na lugoslávia: "Informatika", publicado pelo Centro Nacional de Documentação Técnica e Científica - JCTND $(149,152)$.

3) Na Hungria: "Informatika", publicado pelo Instituto de Informação Técnica e Científica do Ministério da Indústria e Metalurgia $(148,150)$.

4) Na Tchecoslováquia: o periódico "Bulletin Technickych a Ekonomickych Informaci", publicado pela UVTEI, passou a intitular-se "INFORUM", abreviatura de "Informacne Forum" (155).

5) Na União Soviética: a revista "Nauchno-Tekhnicheskaya Inforciya" (Informação Científica e Técnica), publicada desde 1961, pelo VINITI, encerrou sua publicação em 1969, passando a ter o título "Informatika", em 1970 (151). A tradução inglêsa do mesmo periódico passou a denominar-se "Informatics" (295).

No Brasil foram realizados, sob auspícios do IBBD, respectivamente, em novembro de 1968 e de 1969, um "Seminário Sôbre Informática" (298) e o 2 \% Congresso Regional de Documentação da América Latina (57) com 2 sessões dedicadas 
à informática; e sob o patrocínio do CETEB, em Brasília, um "Seminário sôbre Automação da Documentação", em maio de 1969, no qual foram apresentados trabalhos sôbre Informática (300). Em Portugal, sob orientação do INE, teve lugar, de 23 de junho a 4 de julho de 1969, um "Seminário de Informática" (301). Pelo Decreto-lei no 49.009/69, o Govêrno português incluiu obrigatòriamente a Informática nos cursos de preparação de bibliotecários, arquivistas e documentaristas (268, 269).

O têrmo Informática foi criado pelos cientistas A. A. Khorkevich, Phillippe Dreyfus, e J. G. Dorfmann $(223,359)$, tendo como base "Information", com o acréscimo do sufixo "ics", resultando "Informatics", como o processo de formação do nome de várias outras ciências, tais como: matemática (mathematics), cibernética (cybernetics), semiótica (semiotics), astronáutica (astronautics), biônica (bionics), eletrônica (electronics) etc. Os professôres brasileiros Lywal Salles $(284,285)$ e Antônio Garcia de Miranda Neto (232), em trabalhos atuais estudaram as acepções do têrmo. Lasso de la Vega, em seu mais recente livro, afirma que "para la práctica de la investigación, científica e técnica, es indispensable también dominar las técnicas de la documentación o conjunto de normas o procedimientos que integran la llamada informática" (186). Beyssac (28), na França, também publicou uma bibliografia sôbre "Informatique et les bibliothèques". Mikhailov, ao propor o uso da palavra Informática, explica a gradação existente entre informação, informação científica e atividades de informação. Borko (33) e Taylor (338) procuram diferenciar a Informação da Documentação, estabelecendo que a última é um dos muitos componentes da primeira.

Dreyfus, um dos criadores do têrmo, explica que Informática é o tratamento automático e racional da informação considerada como base do conhecimento e da comunicação, e divide-a em:

1) Informática formal ou analítica, que procura os algoritmos mais adequados para o tratamento da informação;

2) Informática sistemática e lógica, que estuda a estrutura dos sistemas de informação, compreendendo os computadores e os operadores que controlam seu funcionamento;

3) Informática física e tecnológica, que analisa os componentes eletrônicos que entram na realização material dos sistemas de informação, compreendendo a

"grosso modo" o que os norte-americanos chamam de "hardware"; 
4) Informática metodológica, que examina os métodos de programação e exploração dos ordenadores (computadores) e outros equipamentos cibernéticos, equivalendo também a "grosso modo", ao que os norte-americanos chamam de "software";

5) Informática aplicada, que estuda os setores onde se pode aplicar o processamento automático e racional da informação, desde a física nuclear até a literatura ou a música.

É neste campo que os especialistas das diversas disciplinas cientificas ou humanísticas, ou das diversas tecnologias terão que colaborar com os peritos em computação; como se pode comprovar pelos assuntos discutidos na conferência conjunta da FID/IFIP sôbre mecanização da armazenagem, recuperação e disseminação da informação, realizada em Roma, 1968 $(88,146)$.

\section{CONCLUSÃO}

Para resumir a evolução do conceito de Biblioteconomia, Documentação e Informática, podemos afirmar que os têrmos reúnem, respectivamente, as seguintes idéias:

a) Biblioteconomia - 1) ciência relativa à organização $e$ administração de bibliotecas; 2) técnica do processamento da informação primária, principalmente através da descrição bibliográfica.

b) Documentação - 1) coleção de documentos; 2) lista de documentos; 3 ) campo de atividade; 4) ramo da ciência ou do conhecimento que estuda as bases teóricas da atividade documentalógica, sua metodologia e técnica.

c) Informática - 1) ciência que estuda o aspecto teórico e prático das atividades concernentes à coleção, processamento, armazenagem, recuperação e disseminação da informação/documentação, através da mecanização e da automação; 2) sistema de informação/documentação relativo a um determinado ramo do conhecimento com o emprêgo de equipamento cibernético, como p. ex. Informática agrícola, Informática aeronáutica etc.

Loojes (199) levantou a idéia da criação de um têrmo nôvo para "amalgamar" os conceitos da "biblioteconomia e documentação". Koblitz (176) justificou a introdução de uma alternativa lingüistica razoável para acoplar "informação e documentação". O têrmo "informática", a nosso ver, atende a essas duas necessidades. Em apoio à nossa opinião está Klempner (173), que 
após estudo exaustivo da expressão "ciência da informação" considera-a inadequada, declarando: "Perphaps we should have done what has been done in U.S.S.R., i.e., adopt the term INFORMATICS rather than information science, to reflect more adequately the theoretical, applied and social aspects of our field".

Em conclusão, Informática é um têrmo nôvo que, reunindo três idéias fundamentais, Homem + Máquina + Informação (71), significa o conjunto das ciências relacionadas com o estudo da informação, em todos os seus aspectos (223), teóricos, aplicados e sociais, englobando, ou estando ligada, em gradações diversas, a outras ciências, tais como, Biblioteconomia, Bibliografia, Documentação, Reprografia (58, 86, 92, 113, 158, 266), Teoria da Informação Matemática $(37,82,278)$, Comunicação (3, 39, 79, 132, 231, 254, 294), Cibernética (232, 340), Semiótica (302), Biologia, Lógica Simbólica (309), Mecânica (82), Estatística (82), Sociologia $(120,216)$, Psicologia $(245,277)$, Eletrônica (131, 188), Automação, Semântica e Lingüística $(67,135$, 140, 156, 201, 204).

Para Malclés (208) a Documentação não é nada mais do que a "Bibliografia ultrapassada em sua marcha", e enquanto a "bibliografia segue os fatos, a documentação marcha ao lado dêles". Parafraseando a ilustre bibliotecária da Sorbone, podemos dizer que a Informática é a documentação interrelacionada no seu conteúdo e automatizada em sua marcha, e enquanto a documentação marcha ao lado dos fatos, a Informática, cibernetiza os mesmos.

A problemática da explosão documental (com 7 milhões de páginas impressas anualmente e $1 / 10$ delas contendo informação científica, com cêrca de quase 200.000 revistas científicas contendo 4,5 milhões de artigos (321), com 225.000 monografias publicadas em 1968, o que dobrou a produção de 1945 , com $4 \%$ de aumento anual (198), e a multiplicidade de línguas em que a informação é disseminada, pois a partir de 1967 (9) o inglês, o francês e o alemão só cobrem $53 \%$ do total publicado), sòmente poderá ser equacionada e resolvida pela Informática.

A partir da década de 70 , ano em que a FID celebra o seu "Jubileu de Diamante" (75 anos de existência), o vocábulo Informática passará a integrar definitiva e internacionalmente a terminologia tecnológica e a estrutura constitutiva do pensamento científico (122) e representará a transformação dos conceitos que foram fornecidos, inicialmente, pela Biblioteconomia e depois pela Documentação, confirmando, assim, o que já dizia Heráclito (141) em 513 a.C.: nada é permanente no mundo, exceto a mutação. 


\section{REFERENCIAS BIBLIOGRÁFICAS}

1. ADAMS, A. Information - a national resource. American Documentation 7(2):71-75. 1956.

2. - The scientific revolution and the research library. Library Resources and Technical Services 9(2):133-142. 1965.

3. AMERICAN DOCUMENTATION INSTITUTE: Annual Meeting. 26. Chicago, 1962. Automation and scientific communication. Short papers contributed to the theme sessions, edited by H. P. Luhn. Chicago, ADI, 1963. $382 \mathrm{p}$.

4. . Parameters of information science. Washington, D.C., ADI, 1964. pp. 31-77.

5. AMERICAN LIBRARY ASSOCIATION. Committee on accreditation. Graduate library school programs accredited by ALA. Chicago, ALA, 1970. 2 p.

ANGLO-AMERICAN CONFERENCE on the Mechanization of Libraries, ver Itens 55 e 213.

6. ANNUAL REVIEW of information science and technology, edited by Carlos A. Cuadra. V. 1-2, 1966-1967. New York, Interscience; v. 3, 1968; v. 4, 1969, Chicago, Encyclopaedia Britannica. (Muitos capítulos em cada volume incluem bibliografias extensas).

7. ARAUJO, J. E. G. El IICA en los 70: una proyección hemisférica y humanista. San José, Costa Rica, IICA - DG, 1970. (Discurso proferido em 18-4-1970 na reunião da Junta Diretiva del IICA em Mar del Plata, Argentina).

8. ARCHAMBAULT, P. Participation et information. Humanisme et Entreprise 36:13-17. 1966.

9. ARNTZ, H. Causes of the information crisis. In Federação Internacional de Documentação, FID General Conference and International Congress on Documentation, 33rd, Tokyo, September 12-22, 1967. Opening session plenary lecture, Tokyo, Science Council of Japan, 1967.

Também em japonês com o título: Johono Kikio Motarasumono. Dokumentesyon Kenkyu 18(1):2-5. 1968.

10. Documentatio a documento. Nachrichten fur Dokumentation 5(4):171-179. 1954.

11. - Das ICSU/UNESCO Projekt - UNISIST. Nachrichten fur Dokumentation 20(1):36-38. 1969.

12. - Das neue Programm der Federation Internationale de Documentation (FID) und seine Auswirkingen auf nationale Aktivitaeten. Nachrichten fur Dokumentation 17(1-2):38-40. 1966.

13. ARTANDI, S. An introduction to computers in information science. Metuchen, N. J., Scarecrow Press, 1968. 145 p.

14. ASHWORTH, W., ed. Handbook of special librarianship and information work. London, ASLIB, 1955. 387 p. (2d ed. 1962, e outras).

15. Librarianship and other disciplines. ASLIB Proceedings 18(6):152-159. 1966.

16. AUBRAC, R. Empleo en la FAO de métodos modernos para documentación en el sector de la agricultura. In Reunión Interamericana de Bibliotecarios y Documentalistas Agrícolas, 2a., Bogotá, Diciembre 2-7, 1968. Actas y trabajos presentados. Bogotá, AIBDA, 1968. pp. VE 1-VE 9.

17. BAGLEY, D.E. Computers in libraries: a selected bibliography. Hatfield (Inglaterra), Hatfield College of Technology Library, 1966. 15 p. 
18. BALBIS, B. L'insegnamento della documentazione in Italia: aspetti, esperienze, probleme relativi alla Publica Ammistrazione. Produttivitá 16(11):20-24. 1965.

19. L'insegnamento professionale della documentazione in Italia. La documentazione in Italia. Roma, Consiglio Nazionale delle Richerche, 1952. 67 p.

20. BALZ, C. E. e STANWOOD, R. H., ed. Literature on information retrieval and machine translation. 2d ed. Gaithersburg, IBM, 1966. 168 p.

21. BARTH, F. G. Die allgemeinbildenden Bibliotheken und die Einrichtungen der Dokumentation - Information. Der Bibliothek 17(8):803-815. 1963.

22. BARZUN, J. The new librarian to the rescue. Library Journal $94(19): 3965$. 1965.

23. BASSET, E. P. An annotated guide to automated library systems. St. Paul, 3M Company, 1968. 15 p.

24. BATTEN, W. E. The future of information work. ASLIB Proceedings 19(6):163-172. 1967.

25. BEARMAN, H. K. G. Automation and librarianship - the computer era. In Proceedings, papers and summaries, of discussions at the public libraries conference held at Brighton, 23rd to 26th September, 1968. London, The Library Association, 1968. pp. 50-55.

26. BENEDE, J. e DACZER, E. Librarianship and documentation: a report on the discussion held at the 1966 IFLA. Conference in The Hague. Tudományos és Múszaki Tájékoztatás (Hungria) 13(9-10):807-820. 1966.

27. BERRY, J. It's a wise child. Library Journal 90(19):4724. 1965.

28. BEYSSAC, R. Notes bibliographiques sommaires sur l'informatique et les bibliothèques. Bulletin de I'Association des Bibliothécaires Français 60: 183-188. 1968.

29. BJORKBOM, C. The history of the word "documentation" within the FID. Revue de la Documentation 26(1):68-69. 1959.

30. BLEK, A. V. Informatika i bibliografiya. Nauchno-Tekhicheskaya Informatciya Seriya 2(9):3-4. 1968. (Original não consultado, compendiado em LISA (1):10. 1969).

31. BONFONTI, C. Función formativa de la información científica. Boletin para Bibliotecas Agrícolas (IICA, Costa Rica) 7(1):1-7. 1970.

32. BONN, G. S. Training and education for information work. American Documentation 13(3):301-362. 1962.

33. BORKO, H. Information science: what is it? American Documentation 19(1):3-5. 1968.

Também em alemão com o título: Informationswissenschaft: Was ist das? Nachrichten fur Dokmentation 19(3):59-61. 1968.

34. BRADFORD, S. C. Documentation. 2nd ed. London, Crosby Lockwood, 1953. pp. $49-55$.

Também em português com o título: Documentação, com introdução do Prof. Jesse H. Shera: tradução de M. E. de Mello Cunha. Rio de Janeiro, Fundo de Cultura, 1961.

35. BRIET, S. Qu'est - ce que la documentation? Paris, Editions Documentaires, Industrielles et Techniques, 1951. 48 p.

36. BRISKMAN, M. A. Bibliografiya i dokumentalistika (informatika). Nauchno - Tekhnicheskaya Informatsiya, Seriya 2(1):3-6. 1968. (Original não consultado, compendiado em Documentation 25(3):271-272. 1969. 
37. BROOKES, B. C. Review of "Proceedings of the Colloquim on information theory". Journal of Documentation 25(3):271/272. 1969.

38. - Review of "On theoretical problems of informatics". Journal of Documentation 25(3):262-264. 1969.

39. BROWN, L. The future of the scientific paper. Journal of Documentation 18(1):1-5. 1962.

40. BRYAN, H. The explosion in published information - myth or reality. Australian Library Journal 17(11):389-401. 1968.

41. BUONOCORE, D. Vocabulario bibliográfico. Santa Fé, Argentina, Castelvi, 1952. pp. 52, 102.

42. BUSH, V. As we may think. Atlantic Monthly 88(7):101-108. 1945.

43. CALESS, T. W. e KIRK, D. B. An application of UDC to machine searching. Journal of Documentation 23(3):208-215. 1967.

44. CARLSON, W. H. What university librarians are thinking, saying and doing about automation; annotated bibliography drawn chiefly from annual reports of university librarians. Corvallis, Oregon State System of Higher Education, 1967. 14 p.

45. CAYLESS, C. F. Bibliography of library automation, 1964-67. London, Council of the British National Bibliography Ltd., 1968.

46. CHOROSZUSZYNA, J. Twenty years of UNESCO's activity. Projects of modifications in the organizational structure and in the programme of activity in the fields of documentation and information. Aktualne Problemy Informacji i Dokumentacji (Polônia) 11 (6): 1 8. 1966.

47. CIGANIK, M. Teaching informatics in the USA. Metodika a Technika Informaci (4):1-16. 1969. (Original não consultado: compendiado em LISA (3):111. 1969).

48. CLAPP, V. W. The future of the research library. Urbana, University of Illinois Press, 1964. $114 \mathrm{p}$.

49. COATES, E. J. Library science and documentation: a new development in international co-operation. The Library Association Record 70(7): 178-179. 1968.

50. COBLANS, H. Introdução ao estudo da documentação. Rio de Janeiro, DASP, 1957.

51. The mechanization of documentation - a tentative balance sheet. in De Reuck, A. e Knight, J., eds. Communication in science: documentation and automation. Boston, Little \& Brown, 1968. pp. $78-83$.

52. ASLIB, 1966. 89 p.

53. COHAN, L. e CRAVEN, K. Science information personnel. The new profession on information combining science, librarianship and foreign language. New York, 1961. $74 \mathrm{p}$.

COLLOQUIUM ON Information Theory, ver RENY, A.

54. COMECON DICTIONARY on Informatics. FID News Bulletin 20(1):4. 1970. COMISSÃO PARA ÁSIA/OCEÂNICA DA FEDERAÇÃO INTERNACIONAL DE DOCUMENTAÇAOO, ver Item 104.

COMISSÃO LATINO-AMERICANA DA FEDERAÇAOO INTERNACIONAL DE DOCUMENTAÇAO, ver Item 105. 
55. COMPUTERS IN libraries: reports on the Anglo-American Conference on Mechanization of Library Services, held at Oxford, June 30-July 3, 1966. Nature 211(5045):128-129. 1966.

56. CONGRESSO REGIONAL DE DOCUMENTAÇÃO. 1. México, 1967. Acta y conclusiones de la VII Reunión FID/CLA y Congreso Regional de Documentación, México, 28 de Agosto - 1.o Septiembre, 1967. Santiago, CENID, 1968. (Folletos de difusión FID/CLA, n.o 11).

57. - 2.9 Rio de Janeiro, 1969. Anais do $2 . \%$ Congresso regional sôbre documentação e 9a Reunião da FID/CLA. Rio de Janeiro, $23 / 28$ novembro, 1969 . Rio de Janeiro, IBBD, 1970. pp. 113-278.

Também em: FID News Bulletin 20(2):13. 1970.

58. CONSEJO INTERNACIONAL DE REPROGRAFIA. In Bibliografia, Documentación, Terminología 10(1):21. 1970.

59. COOK, J. The science information problem. Advancement of Science 23(112):305-309. 1966.

60. CUADRA, C. A. Progress in documentation. In Federação Internacional de Documentação - FID - General Conference and International Congress on Documentation, 33a Tokyo, september 12-22, 1967. Tokyo, Science Council of Japan, 1967. 16 p.

61. DAHL, S. Histoire du livre de l'antiquité a nos jours. 2ème ed. Paris, Editions Poinat, $1960.341 \mathrm{p}$.

62. DALE, H. L. Breaking the information network barrier. Special Libraries 60(1):17-20. 1969.

DANIELS, Marietta ver SHEPARD, M. D.

63. DEFINITIONS OF documentation. American Documentation 6(3):208-209, (4):254-255. 1955.

64. DELAVENAY, E. The UNESCO Department of Documentation, Libraries and Archives: aims and prospects. UNESCO Bulletin for Libraries 21(3):136-139. 1967.

65. DELBOR, L. e DUMORT, J. C. L'informatique au services de la documentation bibliographique dans les sciences de la terre. A.N.R.T. Information et Documentation (8): 8:20. 1968.

66. DEMBOWSKA, M. Bibliotekarstivo $\mathrm{i}$ bibliografia a dokumentacja. In $\mathbf{Z}$ zagadnien teorii $\mathrm{i}$ praktyki bibliotekarskiej. Wroclaw, 1961. pp. 169-182.

67. DEWEZE, A. Traitement de l'information linguistique. Paris, Dunod, 1961. $214 \mathrm{p}$.

68. DE REUCK, A. e KNIGHT, J. eds. Communication in science: documentation and automation. Boston, Little \& Brown, 1968.

69. DIRECTORY OF the Association of American Library Schools. Journal of Education for librarianship 9(3):197-273. 1969.

70. DITMAS, E. M. R. Definition of documentation. College and Research Libraries 10:332. 1949.

Também em: Chambers Encyclopaedia. 1950. v. 4, pp. 575-576.

71. DOLAN, F. T. The role of information scientist. International Journal of Man-Machine Studies 1(1):39-50. 1969.

72. DONKER DUYVIS, F. Die Entstehung des Wortes "Dokumentation" im Namen der FID. Revue de la Documentation 26(1):15-16. 1959.

73 DONNELLY, F. D. Innovation vs. tradition; needed: new definitions of librarianship. APLA Bulletin 33(2):6-12. 1969. 
74. DONOHUE, J. C. Librarianship and the science of information. American Documentation 17(3):120-123. 1966.

75. - e KARIOTH, N. E. Coming of age in Academe - information science at 21. American Documentation 17 (3):117-119. 1966.

76. DUBOIS, G. The FAO documentation service - an experiment to help the developing countries. In Congreso Mundial de la IAALD, 4a Paris, Abril $20-25,1970.11+14$ p.

77. DYSON, G. M. e FARRADANE, J. E. L. Education in information work. The syllabus and present curriculum of the Institute of Information Scientists. Journal of Chemical Documentation 2(2):74-76. 1962.

78. EDWARDS, T. Library and information science abstracts: A new service for librarians and documentalists. The Library Association Record 71(2):41-43. 1969.

79. EGAN, M. E. ed. The communication of specialized information. Chicago, ALA, 1954. $128 \mathrm{p}$.

Também em: American Documentation 4(3-4). 1953.

80. ELIAS, A. W. ASIS; responsibility. American Documentation 19(1):2. 1968.

81. ENCYCLOPAEDIA OF Library and information Science. Editors: Allen Kent, Harold Lancour, William Z. Nasri. New York, Marcel Dekker, v. 1, 1968. (O número total de volumes será 12).

ERICKSON, Ana María Paz de, ver PAZ DE ERICKSON, A. M.

82. FAIRTHORNE, R. A. Mathematics, mechanics and statistics for the information science curriculum; or, What mathematics does an information scientist need? American Documentation Institute. Proceeding, 26th Annual Meeting, Chicago, III. October 1963. p. 39.

83. FARRADANE, J. The future of information work. ASLIB Proceedings 12(5):191-199. 1960.

84. Introducing technical information into present education curricula. Revue de Documentation 28(2):41-45. 1961.

85. FARRADANE, J. Standards in education in information science. ASLIB Proceedings 21(1):32-36. 1969.

86. FEDERAÇÃO INTERNACIONAL DE DOCUMENTAÇÃO. Document reproduction surveys. The Hague, FID, 1954 a 1960 . Suplementos anuais ao item - 1961 a 1965. Suplementos trimestrais na Revue Internacionale de Documentation; $1966 \mathrm{em}$ diante, Suplementos trimestrais no FID News Bulletin.

87. Documentation. 35th. Buenos Aires, September 14-24, 1970.2 2nd Annoucement. Buenos Aires, Consejo Nacional de Investigaciones Científicas y Técnicas, Centro de Documentación Científica, 1970. 16 p.

88. . FID/IFIP Conference on Mechanized Information and Dissemination. Rome, June, 1967. Proceedings. Amsterdam, North Holland, 1968. 729 p. (FID Publ. 146).

89. and information work. The Hague, FID, 1969. 300 p. (FID Publ. 461).

90. Honorary fellows. In Yearbook 1970. The Hague FID, 1970. p. 7. 
91.

formation Work international Conference on Education for Scientili In1967. 270 p. (FID Publ. 422).

92. - Manual on document reproduction. The Hague, FID, 1953-1958. (FID Publ. 264).

93. - Mezhdunarodnyi Forum po Informatike/International Forum on Informatics. Moscow, FID/VINITI, September 1968. Moscow, VINITI, 1969. 2 v.

94. New FID programme. The Hague, FID, 1970. 7 p. (FID Doc. b-7) 18 , restrict to Council members).

95. - On theoretical problems of informatics. Moscow, VINITI, 1968. 203 p. (FID Publ. 435).

Também em russo com o título: Teoreticeskie problemy informatiki, Sbornikstatey. Moscow, VINITI, 1969. 192 p. (Em 1970 aparecerá o v. 2).

96. . Outline of a longterm policy. The Hague, FID, 1960. 39 p. Também em português, espanhol e francês.

97. - Proceedings of the Seminar on UDC in a Mechanized Retrieval System, Ist. Copenhagen, September 1-6, 1968, Copenhagen, FID/CR Secretariat, Danamarks Tekniske Bibliotek, 1970. 180 p. (FID/CR report $n$ ? 9).

98. Projecto de nôvo programa. Cadernos de Biblioteconomia, Arquivistica e Documentação (Portugal) 6(3):156. 1969.

99. - Publications catalogue 1970. The Hague, FID, 1970. 40 p. (FID Publ. 458).

100. - Report of the Secretary General on the activities of FID in 1969. The Hague, FID, 1970. $15 \mathrm{p}$.

101. Statement on a new FID programme to meet changing information patterns. The Hague, FID, 1966. 7 p. (FID Publ. 404).

102. pp. 71-78. (FID Publ. 459).

103. 459).

104. FEDERAÇÃO INTERNACIONAL DE DOCUMENTAÇÃO, COMISSÃO ASIA/ OCEANIA (FID/CAO). First General Meeting of FID/CAO. FID News Bulletin 20(2):13. 1970.

105. COMISSÃO LATINO-AMERICANA (FID/CLA). Informe del Simposio sobre Planificación de la Documentación en los Países en Desarrollo, Bad Godesberg, November 28-30, 1967. Santiago, Chile, Secretaría de la FID/CLA, CENID, 1968. 14 p. (Folletos de difusión FID/CLA, No 8).

FID ver Federação Internacional de Documentação.

106. FILL, K. Dokumentation und Bibliothekswesen. Nachrichten fur Dokumentation 5(3): 119-122. 1954.

107. FISHER, B. Beyond symbiosis: the humanist, the librarian and the computer. Computers and the Humanities 4(1): 19-24. 1969.

108. FONOTOV, G. P. On the problem of the interrelation of scientific information with bibliography and library science. NLL Translation Bulletin 8(8): 670-691. 1966.

Também em russo: Sovetskaya Bibliografiya 93(5): 28-38. 1965. 
109. FOSKETT, D. J. Information service in libraries. London, 1958. 142 p. (2nd ed. 1961.)

110. - Library science in perspective. Herald of Library Science 5(1): 71-74. 1966 .

111. Some basic aspects of classification as an instrument of informatics. In Federação Internacional de Documentação. On theoretical problems of informatics. Moscow, VINITI, 1968. 203 p.

112. FRANCIS, F. The two cultures in information work. ASLIB Proceedings 20(3): 266-277. 1968.

113. FRANK, O. Handbuch der Reprographie. Stuttgart, Dorotheen - Verlag, 1959-1968. 4 v.

114. FRANK, O. ed. Modern documentation and information practices. The Hagua, FID, 1961. p. 12.

Também em espanhol com o título: Técnicas modernas de documentación e información. Buenos Aires, Eudeba, 1964. 228 p.

115. FREEMAN, R. R. e ATHERTON, F. Final report of the research project for the evoluation of the UDC as the indexing language for a mechanized reference retrieval system. New York, American Institute of Physics, 1965-1968. 9 v. (Reports AIP/UDC 1-9.)

116. FREEMAN, W: H. Information. San Francisco, Scientific American, 1966. 218 p.

117. FRY, B. M. Special librarianship and/or documentation. Special Libraries 46(7): 326-327. 1956.

118. GALLO, F. L. R. A propósito de programa da FID/CLA. Fortaleza, Universidade do Ceará, 1963. 13 p. (Trabalho apresentado ao 4 Congresso Brasileiro de Biblioteconomia e Documentação.)

119. GARDNER, F. M. IFLA General Council, 1968. The Library Association Record 71(1): 13. 1969.

120. GARVEY, W. D. e GRIFFITH, B. C. Scientific communication as a social system. Science 157(3792): 1011-1016. 1967.

121. GATES, J. K. Bibliography on automation in libraries. In Gates, J. K. Introduction to librarianship. New York, Mc Graw-Hill, 1968. pp. 398-399.

122. GEYMONAT, L. El pensamiento científico. Traducción de José Babini. Buenos Aires, Eudeba, 1961. p. 5.

123. GILBERT, E. N. Information theory after 18 years. Science 152(3720): 320-326. 1966.

124. GILCHRIST, A. Documentation of documentation. ASLIB Proceedings 18(3): 62-80. 1966.

125. GILL, S. What computers will do. ASLIB Proceedings 19(11): 358-363. 1967.

126. GJESDAL, T. Unesco's documentation activities. FID News Bulletin 17(1): 2-3. 1967.

127. GONZALEZ, M. L. XXXIV Sesión de la IFLA, Frankfurt am Main, del 18 al 24 de agosto de 1968. Biblioteconomia (Espanha), 25(67-68): 102-106. 1968.

128. GRAZIANO, E. E. "Machine-men" and librarians: an essay. College \& Research Libraries 28(6): 403-406. 1967. 
129. GROSE, M. W. The place of the librarian in the computer age. The Library Association Record 70(8): 195-197. 1968.

130. GUILHAUMOU, J. Lexique de l'informatique. Paris, Entreprise Moderne d'Edition, 1969. $121 \mathrm{p}$.

131. GUTENMACHER, L. I. Informação electrônica e máquinas logísticas. $2^{\mathrm{a}}$ ed. Moscow, VINITI, 1962. 200 p.

132. GYORE, P. Informática, comunicação, diálogo. Tudományos és Muszaki Tájékoztatás (Hungria) 16(4): 245-255. 1969. (Original não consultado; compendiado de LISA (4):160. 1969.)

133. HAHN, A. e TRABAND, P. Applications de l'informatique a la gestion automatique des services der catalogue et du prêt. Association des Bibliothécaires Français. Bulletin d'Informations (64): 147-164. 1969. HANDBOOK OF Special Librarianship and Information Work, ver ASHWORTH, W. ed.

134. HARLOW, N. Documentation and the librarian. Library Journal 81(9): 1083-1085. 1955.

135. HARTMAN, R. R. K. Linguistics and translation. ASLIB Proceedings 21(5): 190-194. 1969.

136. HAYES, R. M. Data processing in the library schoot curriculum. ALA Bulletin 61(6): 662-669. 1967.

137. The development of a methodology for system design and its role in library education. Library Quarterly 34( ): 340. 1964.

138. tation 20( ): 362-365.

139. Information scienec and librarianship. In IFLA General Council. 35th session, Copenhagen, August 25-30, 1969. FID News Bulletin 19(9): 84. 1969.

140. HAYS, D. G., HENISZ-DOSTERT, B. e HOUSTON, J. I. Computational linguistics: bibliography, 1965. Santa Mônica, Calif., Rand Corporation, 1968. 63 p. 664 ref. (Memorandum RM-5733-PR, AD 673474.)

141. HERÁCLITO DE EFESO. In Enciclopedia Universal llustrada Européa Americana. Madrid, Espasa-Calpe, 1925. v. 27. pp. 1099-1100.

142. HOLZBAUER, H. Mechanized bibliography of documentation and information sciences. Washington, D.C., Dept. of the Interior, 1967. 166 p.

143. HOSELITZ, B. Reader's guide to the social sciences. Glencoe, Illinois, The Free Press, 1961.

144. HUTTON, R. S. ASLIB past and future. ASLIB Proceedings 19(1): 19-28. 1967.

145. IBBD. In Centros de documentación científica y técnica: Paris, UNESCO, 1965. pp. 48-49.

146. IFIP - Its origins, aims and achievements. Data Processing Magazine 9(1): 44-45. 1967.

147. INFORMATIK: Information and Dokumentation in Wirtschaft, Wissenschaft und Technik. Berlin, Zentralinstitut fur Information und Dokumentation, 1969.

148. INFORMATIKA. Budapest. Institute for Technical and Scientific Information, Ministry of Metallurgy and Machine Industry, 1967. v. 1 (trimestral). 
149. INFORMATIKA: Casopis za teoriju i praksu naucnih, technickih i ekonomskih informacija $\mathbf{i}$ dokumentacije. Belgrade, Jugoslovenski Centar za Tehnicku i Naucnu Dokumentacija 1967. v. 1 (6 vêzes por ano).

150. INFORMATIKA: New journal in Hungary. FID News Bulletin 18(2): 16. 1968.

151. INFORMATIKA: New title of the Russian Nauchno-Tekhnicheskaya Informaciya. FID News Bulletin 19(8): 78. 1969.

152. INFORMATIKA: New Yugoslav documentation journal. FID News Bulletin 18(2): 16. 1968.

153. INFORMATION ACTIVITIES of Mayor International Organizations. Paris, OECD, 1969. 170 p.

Também em francês com o título: Activités des principales organizations internationales dans le domaine de la documentation.

154. INFORMATION SCIENCE Abstracts. Philadelphia, Documentation Abstract Inc., 1966. v. 1 (1966-1968, v. 1-3: Documentation Abstracts).

155. INFORUM: new Czech journal. FID News Bulletin 20(3): 28. 1970.

Também em: Zentralblatt fur Bibliothekswesen 83(11). 1969.

156. INTERNATIONAL CONFERENCE ON COMPUTATIONAL LINGUISTICS. Sanga-Saby, September 1-4, 1969. FID News Bulletin 20(2): 14. 1970. Também em: Computers and the Humanities 4(3): 1970.

INTERNATIONAL CONFERENCE ON EDUCATION FOR SCIENTIFIC. Information Work, ver Item 91.

157. INTERNATIONAL CONFERENCE ON SCIENTIFIC INFORMATION. NOvember 16-21, 1958. Proceedings. Washington, D.C., National Academy of Sciences - National Research Council, 1959. 2 v.

158. INTERNATIONAL CONGRESS ON REPROGRAPHY. 3 ? London, March 8-12, 1971. FID News Bulletin 19(3): 26-27. 1969.

159. INTERNATIONAL DIRECTORY OF COMPUTER and Information Services. London, Europa Publications, 1969. 338 p.

INTERNATIONAL FORUM ON INFORMATICS, ver Item 93.

160. INTERUNIVERSITY COMMUNICATION COUNCIL (EDUCOM) Agricultural Sciences information network development plan. Beltswille, Md., National Agricultural Library, 1969. p. irr. (Research report RR 169).

161. ISAKOVIC, D. La documentologie. Revue Internationale de la Documentation 32(4): 152-153. 1965.

162. IVANOV, M. V. The international nuclear information system-INIS. FID News Bulletin 20(1): 9. 1970.

163. JACKSON, E. B. Inside documentation. Special Libraries 34(4): 151157. 1954.

164. JONES, V. L. Changing concepts of librarianship. Kentucky Library Association Bulletin 33(1): 5-15. 1969.

165. KENT, A. Documentation. Library Trends 10(2): 224. 1961.

166. KERVEGANT, D. e FOURMONT, R. Bibliographies et documentation: insuffisances, problémes et perspectives. Bulletin des Bibliothéques de France 5:113-125, 6:157-168. 1960. 
167. KIBBEE, J. M. The information explosion: some requirements on the public administrator. Mayor and Manager 11(1): 8-9. 1968.

168. KIMBER, R. T. Automation in libraries. Long Island City, N. Y., Pergamon Press, 1968. 140 p. (International series of monographs in library and information science, v. 10).

169. Press, 1968. pp. 134-138.

170. KING, A. The place of documentation today. Revue de la Documentation 23(1): 1-3. 1956.

171. KING, A. International trends in librarianship and documentation. Bibliotheekleven (Holanda) 46(9): 489-491. 1962.

172. KLEMPNER, I. M. Information centres and continuing education for librarianship. Special Libraries 59(9): 729-732. 1968.

173. A unified curriculum for information sciences. College \& Research Libraries 30(4): 335-341. 1969.

174. KOBLITZ, J. Das begriffliche Verhaltnis der Information zur Dokumentation. Dokumentation 8(1): 2-12. 1960.

175. - Dokumentation und Information. Eine terminologische Untersuchung. Dokumentation 7(6): 172-173. 1959.

176. L Librarianship and information-documentation: distinctive and common features. In Federação Internacional de Documentação. On theoretical problems of informatics. Moscow, VINITI, 1969. pp. 120-142.

177.

. Die Terminologie fur die Fachgebiete Dokumentation und Information und ihre Bedeutung fur die internationale Zusammenarbelt. Dokumentation 11(4): 97-101. 1963.

178. KRIKELAS, J. Library applications of data processing on enumerative bibliography, 1964-65. In Clinic on Library Applications of data processing, University of Illinois, 4th, 1966. Proceedings. Edited by Herbert Goldhar. Champaign, 1966. pp. 211-218.

179. KRIKELAS, J. Library applications of data processing: a select bibliography, 1963-64. In Clinic on library applications of data processing, University of Illinois, 3d, 1965. Proceedings. Edited by Francis B. Jenquins. Champaign, 1966. pp. 193-291.

180. KUNZE, H. Bemerkungen zum Thema "Wissenschaftliche Bibliotecheken und Dokumentation". In Bibliothek, Bibliothekas, Bibliothekswissenschaften. Leipzig, 1954. pp. 203-213.

181. kumentation 1(4): 78-84. 1953-54.

182. LACLEMANDIERE, J. Les cadres et la documentation. Informations UFOD 8:6. 1962.

183. LASSO DE LA VEGA, J. Bibliotecario y documentalista, una fricción y un problema. Revista de Arquivos, Bibliotecas y Museos (Espanha) 60(2): 451-470. 1954.

184. p. 335 .

185. Documentación en España. Boletín de la UNESCO para las Bibliotecas (3): 163-168. 1963. 
186. 107-108.

187. LAZARESCU, G. Modern information systems applied on a world scale - a comparative study. Studü si Cercetári de Documentare si Bibliologie (Rumánia) 8(4): 423-437. 1966.

188. LETHEVE, J. La Bibliothéque de demain ser-t-elle électronique? Bulletin de l'Association des Bibliothécaires Français 54:7-10. 1967.

189. LIBRARIANSHIP \& DOCUMENTATION. Libri 16(3): 205-220. 1966.

190. LIBRARY \& INFORMATION SCIENCE ABSTRACTS. London, The Library Association \& ASLIB, 1969. v. 1 (De 1950-1968, v. 1-19: Library Science Abstracts).

191. LIBRARY FROFESSIONALISM Vis-a-Vis the computer. In Automation problems of 1968 , October $4-5,1968$. Purdue University Libraries. Edited by Theodora Andrews. Lafayette, Indiana, Purdue University, 1969. pp. $17-39$.

192. LICKLIDER, J. C. R. Libraries of the future. Cambridge, Mass., MIT Press, 1965. $1 \mathrm{v}$.

193. LIEBESNY, F. Career development. ASLIB Proceedings 18(1): 23-26. 1966.

194. LIPETZ, B. A. A view of the special library of the future. Drexel Library Quarterly 5(4): 195-208. 1969.

195. LLORCA ZARAGOZA, V. Ibero-American Seminar on Planning of Library and Documentation Services. UNESCO Bulletin for Libraries 22(4): 166-172, 188.1968.

196. LLOYD, G. A. Open address on the future of UDC. In Seminar on UDC in a Mechanized Retrieval System, 1st. Copenhagen, September $1-6,1968$. Proceedings. Copenhagen, FID/CR Secretariat. Danamarke Tekniske Bibliothek, 1970. 180 p. (FID/CR Report $n$ ? 9).

197. LLOYD, G. A. The UDC in its international aspects. ASLIB Proceedings 21(5): 204-208. 1969.

198. LONDON, G. The publication inflation. American Documentation 19(2): 137-141. 1968.

199. LOOSJES, TH. P. More documents - more inquires - more mechanization: some impressions of the 32nd IFLA Congress on Libraries and Documentation at Scheveningen, Netherlands. Quarterly Bulletin of IAALD 12(1/2): 1-2. 1967.

200. . On documentation of scientific literature. Translated by A. J. Dickson. London, Butterworths, 1967. pp. 1-8.

201. McBURNEY, R. E. Technical information for industry. In Symposium on Scientific and Technical Information, Lourenço Marques, July, 1968. Ottawa, National Research Council, 1968. 32 p.

202. MCCARTHY, J. Information. Scientific American 215(3): 64-73, 312. 1966.

203. MCCUNE, L. C. e SALMON, S. R. Bibliography of library automation. ALA Bulletin 61(6): 674-675, 678-694. 1967.

204. MacDONALD, R. R. Linguistic structure. In Newman, S. M. ed. Information systems compatibility. Washington, D.C., Spartan Books, 1965. pp. 85-102. 
205. MAJEWSKI, Z. Princípios de documentação científica e técnica e o papel do Instituto a ela dedicado. (Em polonês.) Zycie Nauki (Polônia) 3:277-291. 1951.

206. In Federação Internacional de Documentação. FID General Conference and International Congress on Documetation, 33a Tokyo, Science Council of Japan, 1967. 6 p.

207. MALCLĖS, L. N. La Bibliographie. Paris, 1956.

Também em espanhol com o título: La Bibliografía. Buenos Aires, Eudeba.

208. - Cours de bibliographie. Géneve, Droz, 1954.

209. Notions fondamentales de bibliographie. Géneve, Droz, 1955.

210. - Les sources du travail bibliographique. Géneve, Droz, 1950.

211. MALUGANI, M. D. Acceso regional a la información en ciencias agrícolas: la experiencia en América Latina. Presentado a la Reunión de Expertos en Documentación Científica, OEA/DAC e ICFES, Bogotá. Febrero $17-20,1970.36 \mathrm{p}$.

212. formación en América Latina. Turrialba, Costa Rica, IICA, 1970. 38 p. (Trabalho apresentado ao $40^{\circ}$ Congresso Mundial da Associação Internacional de Bibliotecários e Documentalistas Agrícolas, IAALD, Paris, $20-25$ de abril, 1970 . Contém em apêndice: Literatura bibliotecológica y de documentación agrícola latino-americana. Turrialba, Costa Rica, IICA-BSD, 1970. 19 p.)

213. MARKUSON, B. E. Report on the Anglo-American Conference on the Mechanization of Libraries, held in Oxford, England, June 20, July 3 , 1966. Library of Congress Information Bulletin 25(28): 393-396. 1966.

214. MARTIN, L. A. The changes ahead. Library Journal 93(15): 711-716. 1968.

215. MASON, C. Bibliography of library automation. ALA Bulletin 63(8): 1117-1134. 1969. (ERIC/CLIS Bibliography series, $n$ \% 2.)

216. MENZEL, H. Scientific communication: five themes from social science research. American Psychologist 21:998-1000. 1966.

217. MEREDITH, G. P. Information documentation and communication. Library Association Record (6):191-196. 1961.

218. MERTA, A. Informatics as a scientific discipline. In Federação Internacional de Documentação. On theoretical problems of informatics. Moscow, VINITI, 1968. 203 p.

219. MERTA, A. Informatics as a branch of science. In On theoretical problems of informatics. Moscow, VINITI, 1969. pp. 32-40.

220. Is informatics a separate discipline, science or technical work with sources of information? Metodika a Technika Informaci (9): $1-12$, 1968. (Original não consultado; compendiado de LISA (21): 58. 1969.)

221. MEYRIAT, J. Vers une révolution technique dans la documentation? Revue de la Documentation 24(4): 137-140. 1957. 
222. MIKHAILOV, A. I. Aims and purpose of scientific information. UNESCO Bulletin for Libraries 13(11/12): 262-265. 1959.

223. $\longrightarrow$ Informatics: a scientific discipline. Moscow, VINITI, 1967. 7 p.

224. Problems of mechanization and automation of information work. Revue Internationale de la Documentation 29(2): 49-56. 1962.

225. CHERNYI, A. J. e GILYAREVSKII, R. S. The development of informatics in the USSR. Washington, D.C., Joint Publications Research Service, 1968. 12 p.

Também em russo: Naucho Teckhnicheskaya informatsiya, Series 2(11): 3-18. 1967.

226. MIKHAILOV, A. I. Fundamentos da informática (Osnovy informatiki). Moscow, VINITI, 1968. 756 p.

227. - Informatics - a new name for the theory of scientific information. Nauchno-Tekhnicheskaya Informatsiya 12:35-39. 1966.

Também em inglês com o mesmo título em: FID News Bulletin 17(7): 70-74. 1967; e em japonês com o título: Informatics - Kagaku Johono Risonni taisuru atarashii Meisho. Dokumentesyon Kenkyu 18(3): 74-79. 1968.

228. - Informatics, its scope and methods. In Federação Internacional de Documentação. On theoretical problems of informatics. Moscow, VINITI, 1969. pp. 7-24.

229. - Informatik-eine neue wissenschaftliche Disziplin: Gegenstand, Methoden und Bezuhungen zu anderen Wissenschaften. Informatik 16(1): 5-11. 1969. (Original não consultado; compendiado em LISA (3):111. 1969.)

230. MIKHAILOV, O. A. Unesco's documentation activities. FID News Bulletin 19(1): 7. 1969.

231. MILLER, G. R. On defining communication: another stab. Journal of Communication 16(2): 88-98. 1966.

232. MIRANDA NETO, A. G. Informação, documentação e cibernética. In Seminário de Informática, Rio de Janeiro, Novembro 19-21, 1968. Informática, trabalhos apresentados. Rio de Janeiro, IBBD, 1969. pp. 21-38.

233. MIRONESCU, N., STANCOVICI, V. e NEAMTU, O. Informação científica e documentação bibliográfica (Informare stuntifica si documentare bibliográfica). Probleme de Documentare si Informare (Rumânia 1(8): 476-482. 1967.

234. MOHRHARDT, F. E. A librarian looks at documentation. Special Libraries 46(9): 412-416. 1956.

235. MOLLER, A. J. Wisenschaft und Dokumentation. Nachrichten für Dokumentation 5(1): 3-6. 1954.

236. MOLNAR, P. The conception and interrelation of bibliology and library science formulated in recent debates in socialist countries. LIBRI 18(1): 1-34. 1968.

237. MONTGOMERY, E. B. Four "new" sciences: an approach to complexity. In Storage and retrieval of information: a user - supplier dialogue. Proceedings... June $18-30,1968$. Neuilly-sur-Seine, NATO-AGARD, 1968. pp. $41-47$. 
238. MUMFORD, L. Q. Librarians and the everlasting now. Library Journal 91(4): 901-906. 1966.

239. MURDOCK, J. W. e BROPHY, C. A. Jr. A comparison of the functions of libraries and information centers. Library Trends 14(3): 347-352. 1966.

240. NEELAND, F. Bibliography on information science and technology. Detroit, American Data Processing Processing Inc., 1969. 287 p.

241. NELSON, E. Las bibliotecas en los Estados Unidos. New York, Dotación Carnegie por la Paz Internacional, 1927. 406 p. (Biblioteca InterAmericana, v. 6).

242. NEW RESEARCH Departments at the Lenin Library. FID News Bulletin 18(1): 2-3. 1968.

243. NEWMAN, S. M. ed. Information systems compatibility. Washington, D.C., Spartan Books, 1965. 150 p. (American University technology of management series, v. 1).

244. NITECKI, J. Z. Reflection on the nature and limits of library science. Journal of Library History 3(2): 103-119. 1968.

245. NOVIKOV, Y. U. Problemas psicológicos na informática. NauchnoTekhnicheskaya Informatciya, Seriya 2(1): 6-9. 1969. (Original não consultado, compendiado de LISA (4):160. 1969.)

246. NYSTROM, A. UDC for computeraided documentation. Tidskift fôr Dokumentation 24(5):67-70. 1968. Item n? 95.

ON THEORETICAL Problems on Informatics, ver Item no.

247. ORGANIZAÇÃO DA informação técnica do interior da emprêsa. Cadernos de Biblioteconomia, Arquivistica e Documentaçẩo (Portugal) 6(3):145-148. 1969.

248. ORTEGA Y GASSET, J. Misión del bibliotecario. 2a ed. Madrid, Revista de Occidente, 1967. 183 p.

249. OTLET, P. L'Organization internationale de la bibliographie et de la documentation. Bruxelles, 1920. 44p.

250. L'Organization internationale du livre, de al bibliographie et de la documentation. Paris, 1925. 13 p.

Também em: Congrès International des Bibliothécaires et des Bibliophiles. Proces verbaux et Mémories. Paris, 1923.

251.

Bulletin sciences bibliographiques et la documentation.

252. Traité de documentation. Le livre sur le livre. Théorie et pratique. Bruxelles, Editiones Mundaneum, 1934. 431 p.

253. PARKER, E. B. The user's place in an information system. American Documentation 17(1):26-27. 1966.

254. PASSMAN, S. Scientific and technological communication. Oxford, Pergamon Press, 1969. $151 \mathrm{p}$.

255. PAZ DE ERICKSON, A. M. La Asociación Interamericana de Bibliotecarios y Documentalistas Agrícolas, AIBDA. Boletín Bibliográfico Agricola (Costa Rica) 2(4):19-30. 1965. cola en América Latina - Técnicas modernas y cooperación internacional. In Congreso Mundial de la IAALD, 4ํ Paris, Abril 20-25, 1970. 56 p. 
257. PENNA, C. V. El financiamiento de los servicios de bibliotecas y de documentación. Boletín de la UNESCO para las Bibliotecas 22(1):

258. Planeamiento de servicios bibliotecarios. Madrid, Oficina de Educación Ibero-Americana, 1968. 1 v.

259. PEREZ-VICTORIA, A. Hacia un sistema mundial de información científica: una empresa común CIUC-UNESCO. Boletín de la UNESCO para la Bibliotecas 23(1):2-8. 1969.

260. PERREAULT, J. M. Automatized retranslatability of UDC Codes. LIBRI 18(2):120-124. 1968.

261. . An introduction to UDC. London, Clive Bingley, 1969. $111 \mathrm{p}$.

262. TOWARDS a theory of UDC. London, Clive Bingley, 1969. $241 \mathrm{p}$.

263. PIETSCH, E. H. E. Dokumentation und Information auf dem Wege zur Wissenschaft inhalt und Wandel der Begriffe. Nachrichten für Dokumentation 19(6):199-207. 1968.

264. Entwicklungstendenzen im Bereiche von Dokumentation und Information. Nachrichten für Dokumentation 13(4):191-201. 1962.

265. - Grundfragen der Dokumentation. Schriftreihe Arbgemein. Rationalisierung Landes. Nordrhein Westfalen, Helft. 14. 1954.

Também em: Die künftige Entwicklung der Dokumentation. LIBRI 12(4):287. 1963.

PLANIFICACION DE la Documentación en los paises en desarrollo, ver Item 105.

266. POINDRON, P. Manuel practique de reproduction documentaire et de sélection. Paris, Gauthier-Villars, 1964. 343 p.

267. POLUSHKIN, V. A. Toward a definition of the notion "document". Nauchno-Tekhnicheskaya Informatciya 4(5):8-10. 1964.

268. PORTUGAL. Leis, decretos, etc. Decreto-lei $n \div 49.009$ : altera as condições de preparação dos bibliotecários, arquivistas e documentalistas. Diário do Govêrno, I série, Lisboa, Maio 16, 1969, (116):1.

269. PREPARAÇÃO TÉCNICA dos futuros bibliotecários, arquivistas e documentalistas: Decreto-lei $n$ ?̣ 49.009. Cadernos de Biblioteconomia, Arquivística e Documentação 6(3):152-153. 1969.

270. PROYECTO CIUC-UNESCO sobre Información Cientifica. Boletín de la UNESCO para la Bibliotecas 22(2):111-112. 1968.

271. RANGANATHAN, S. R. Depth classification of a bibliography. Annals of Library Science and Documentation 10(2):41. 1963.

272. ed. Documentation and its facets. Being a symposium of 70 papers by 32 authors. London, 1963. $639 \mathrm{p}$.

273. Documentation and its problems. Revue Internationale de Documentation 30(4):127-128. 1963.

274. Scientific and technical information: storage, dissemination and retrieval. Library Herald 4(2):43-51. 1961-1962.

275. Three crises in documentation. In Federação Internacional de Documentação. FID General Conference and International Congress on Documentation, 33rd. Tokyo, September 12-22, 1967. Proceedings. Tokyo, Science Council of Japan, 1967. $10 \mathrm{p}$. 
276. REES, A. M. The impact of computer technology on library education. UNESCO Bulletin for Libraries 23 (1):25-29. 1969.

277. REITMAN, W. R. Cognition and thought: an information - processing approach. New York, John Wiley, 1965. 312 p.

278. RENYI, A. ed. Proceedings of the Colloquim on information theory. Budapest, Janos Bolyai Mathematical Society, 1968. (Original não consultado, compendiado em Journal of Documentation 25(3):271-272. 1969). RIBEIRO, FERNANDA LEITE, ver GALLO, F. L. R.

279. RIGBY, M. Experiments in mechanized control of meteorological and geoastrophysical literature and UDC schedules in these fields. Revue Internationale de la Documentation 31(3):103-106. 1964.

280. ROST, G., comp. Bibliothek und Domumentation: line bibliographische Grundlage für die Diskussion über ein einheitliches Informations system. Leipsig, Deutsche Bücherei, 1963. 36 p.

281. ROTHERY, B. The movement of information. Data Processing Magazine 7(11):54-55. 1965.

282. ROZSA, G. Scientific information and the organization of science. Magyar Tudoman (Hungria) 3:135-145. 1964.

283. SABOR J. R. Métodos de enseñanza de la bibliotecologia. Paris, UNESCO, 1968. 146 p. pp. 68-80. (Manuales de la UNESCO para las bibliotecas, v. 16.)

284. SALLES, L. O mundo da informática. In Seminário de Informática, Rio de Janeiro, Novembro 19-21, 1968. Informática, trabalhos apresentados. Rio de Janeiro, IBBD, 1969. pp. 5-8.

285. . O mundo fascinante da informática. Cadernos de Jornalismo e Comunicação 9:12-17. 1968.

286. SAMBAQUY, L. Q. O IBBD e seus serviços. Rio de Janeiro, IBBD, 1958. $20 \mathrm{p}$.

287. Miembro Honorario de la FID. In Boletim Informativo de AIBDA 5(1):7. 1970.

288. SALMON, S. R. Information science and automation; the newest division. ALA Bulletin 61(6):637-642. 1967.

289. SARACEVIC, T. e REES, A. M. The impact of information science on library practics New York, Special Libraries Association, 1968. 18 p.

290. SAVAGE, T. R. Users versus Documents. American Documentation $17(3): 141.1966$.

291. SCHICK, F. L. ed. North American library education, directory and statistics, 1966-1968. Chicago, ALA, 1968.

292. SCHUR, H. e SAUNDERS, W. L. Education and training for scientific and technological library and information work. London, HMSO, 1968. $79 p$.

293. SCHUMEYER, W. Der Begriff der Dokumentation. Frankfurt/Main, Deutsche Gesellschaft für Dokumentation, 1953. 6 p.

294. SCIENTIFIC \& TECHNICAL Communication: a pressing national problem and recomendations for its solution. A report by the Committee on Scientific and Technical Communication, COMSAT, of NAS-NAE. Washington, D.C., NAS, 1969. 322 p. (NAS Publ. 1707). 
295. SCIENTIFIC \& TECHNICAL Information - change in title to Informatics. FID News Bulletin 20(1):7. 1969.

296. SCOTT, E. IFLA and FID: history and programs. Library Quarterly 31(1):1-18. 1962.

297. SELIGA, J. The information engineer. Aktualne Problemy Informacji i Dokumentacji (Polônia) 11(6):19-22. 1966.

SEMINAR ON UDC IN A MECHANIZED RETRIEVAL SYSTEM, ver Item 97.

298. SEMINÁRIO DE INFORMATICA, Rio de Janeiro, Novembro 19-21, 1968. Informática, trabalhos apresentados. Rio de Janeiro, IBBD, 1969. 108 p.

299. SEMINARIO IBEROAMERICANO SOBRE PLANEAMIENTO DE SERVICIOS BIBLIOTECARIOS Y DE DOCUMENTACION, MADRID, FEB. 5 - MARZO 2, 1968. Informe final. Madrid, Oficina de Educación Iberoamericano/ UNESCO, 1968. $20 \mathrm{p}$.

300. SEMINARIO SÔBRE AUTOMAÇÃO NA DOCUMENTAÇAO, Brasilia, D.F., maio 7-9, 1969. Cadernos de Biblioteconomia, Arquivistica e Documentação (Portugal) 6(3):156. 1969.

Também em: FID News Bulletin 19(6):54. 1969.

301. SEMINÁRIO SÔBRE INFORMATICA, Lisboa, junho 23 - julho 4, 1969. Cadernos de Biblioteconomia, Arquivística e Documentação (Portugal) 6(3):155. 1969.

302. SEMIOTICA: Journal of the International Association for Semiotic Studies, 1970. FID News Bulletin 20(2):16. 1970.

SEMINARIO SOBRE PLANIFICACION DE LA DOCUMENTACION EN LOS PAISES EN DESARROLLO, ver item 105.

303. SHAW, R. R. Beyond 1984 - a reply. ALA Bulletin 61(3):231-232. 1967.

304. Documentation: complete cycle of information service. College and Research Libraries 18(6):452-454. 1957.

305. SHEPARD, M. M. La evolución de los servicios de información científica en los Estados Unidos. Washington, D.C., Unión Panamericana, 1962. 16 p. (Cuadernos bibliotecológicos, no 10).

306. International dimensions of U.S. librarianship. ALA Bulletin 62(6):699-710. 1968.

307. SHERA, J. H. Documentation and the organization of. knowledge. London, Crosby Lockwood, 1966. 185 p.

308. Documentation, its scope and limitations. Library Quarterly 20(1):13-26. 1961.

Também em: Documentation and the organization of knowledge. London, Crosby Lockwood, 1966.

309. An epistemological foundation for library science. In Montgomery, E. B., ed. The foundations of access to knowledge. Syracuse, N. Y., Syracuse University, 1968. pp. 7-25.

310. —. The librarian's new frontier. Library Journal 82(1):26-28. 1957.

311. The quiet stir of thought; or, What the computer cannot do. Library Journal 94(15):2875-2880. 1969.

312.

1(2):189-199. 1952-1953. 
313. Research and development in documentation. Library Trends 6(2):187-206. 1957.

314. SHERA, J. H. What is past is prologue: beyond 1894. ALA Bulletin 61(1):35-47. 1967.

315. - e EGAN, M. E. A review of the present state of librarianship and documentation. In Bradford, S. C. Documentation. 2nd ed. London, Crosby Lockwood, 1953. pp. 11-45.

316. - e KENT, A. e PERRY, J. W. eds. Information systems in documentation. New York, 1957, 639 p.

317. SHERROD, J. National Agricultural Library, Washington, D.C. Inspel 3(2):82-86. 1968.

318. SHILLING, C. W. e BERMAN, B. Science information specialist training program. Washington, D.C., Biological Sciences Communication Project, The George Washington University, 1968. $27 \mathrm{p}$.

319. SHREYDER, O. Alguns problemas da teoria da informação cientifica (Nekotorye problemij teorii nauchnoy informatsii). Nauchono-Tekhnicheskaya Informatciya 6:17-22. 1966.

SIMPOSIO SOBRE PLANIFICACION DE LA DOCUMENTACION EN LOS PAISES EN DESARROLLO, FID/DC, Bad Godesberg, Novembre 28-30, 1967. Ver Item 105.

320. SWOLNIK, H. Brain vs. computer. Journal of Chemical Documentation 6(2): 1966.

321. SMITH, G. L. e MEYER, R. S. Library use of computers: an introduction. New York, SLA, 1969. 114 p.

322. SOS: avalanche de informação. Stenás 21 (1):29-30. 1969. (Original não consultado, compendiado de LISA (2):64. 1969).

323. SPEER, J. Libraries and automation: a bibliography with index. Emporia, Kansas Teachers College Press, 1967. 106 p.

324. STANCOVICI, V. Problemas atuais da documentação científica (Probleme actuale ale documentarii stüntifice. Progresele Stüntei (Rumânia) 1(5):151-154. 1965.

325. SVIRIDOV, F. A. FID and its possible contribution of the study of the feasibility of a world science information system: statement at the First Session of the ICSU/UNESCO Central Comittee to Study the Feasibility of a World Science Information System, UNESCO House, Dec. 6-8, 1967. The Hague, FID 2 p.

326. International projects sponsored by FID. ASLIB Proceedings 20(12):565-573. 1968.

327. International trends in documentation and information services. Library Trends 17(3):326-338. 1969.

328. Introduction. In FID Yearbook 1970. The Hague, FID, 1970. p. 4.

329. SVIRIDOV, F. A. Le programme d'activité de la FID pam 1969. Bulletin de I'UNESCO a I'Intention des Bibliothèques 23(3):153-158. 1969.

330. SWANK, R. C. Documentation and information science in the core library school curriculum. Special Libraries 58(1):40-44. 1967. 
331. SWANSON, R. W. Bibliography: mechanization of library operations. In Move the information: a kind of missionary spirit. Arlington, Air Force Office of Scientific Research, 1967. pp. 157-163.

332. SYMPOSIUM ON EDUCATION FOR SCIENCE. Warrenton, Virginia, September 7-10, 1965. Proceedings. Edited by L. B. Heilpriss, B. E. Markuson and F. L. Goodman. Sponsored by American Documentation Institute. Washington, D.C., Spartan Books, 1965. 175 p.

333. SZENTMIHALYI, J. Development of the theory of scientific information. Tudományos és Müszaki Tajékoztatás 15(8-9): 597-617. 1968. (Original não consultado, compendiado em LISA (1):10. 1969.

334. TAUBE, M. Documentation, information retrieval and other techniques. Library Quarterly 30(1):90-103. 1961.

335. TAUBE, M. Special librarianship and documentation. American Documentation 3(3):166-167. 1952.

336. TAYLOR, R. S. Bibliography of recent reports and books on library automation and library systems analyses. Bethlehem, Center for the Information Sciences, Lehigh University, 1964. $10 \mathrm{p}$.

337. The interface between librarianship and information science andengineering. Special Libraries 58 (1):45-48. 1967.

338. Professional aspects of information science and technology. In Annual Review of Information Science and Technology. New York, Wiley, 1966, v. 1, pp. 15-40.

339. - Review and critique of undergraduate course in the information sciences. Report no 1, Curriculum for the information Sciences. Bethelehem, Center for the Information Sciences, Lehigh University, 1964, p. 2.

340. TEICHMANN, H. Kybernetik und Dokumentation. Nachrichten für Dokumentation 18(1):1-5. 1967.

341. TELL, B. V. Curriculum for a suggested training course for documentalists. Library World 756:346-352. 1963.

342. Scandinavian development in documentation and information services. Library Trends 17(3):289-298. 1969.

THEORETICAL PROBLEMS ON Informatics, ver Item 95.

343. THIESMEYER, L. R. Current efforts to solve the information explosion problem. TAPPI (Estados Unidos) 49(9):74A-76A. 1960.

344. TOWNLEY, H. The use of the computer in information work. ASLIB Proceedings 19(11):369-380. 1967.

345. UNESCO. Centros de documentación científica y técnica: contribución de la UNESCO a su desarrollo. Paris, UNESCO, 1965. $57 \mathrm{p}$.

346. Programme de I'UNESCO en matiére de documentation de bibliothéques et d'archives pour 1969-1970. Bulletin de I'UNESCO a I'Intention des Bibliothéques 23(3):216-238. 1969.

347. World guide to science information and documentation services. Paris, UNESCO, 1965. 211 p.

348. World guide to technical information and documentation services. Paris, UNESCO, 1969. 285 p. 
349. UNISIST PROJECT. FID News Bulletin 18(1):2, 18(6):58-59, 18(8):80, 1968; 19(1):7, 19(2):9-10, 19(12):115. 1969.

350. URQUHART, D. J. Developing user independence. ASLIB Proceedings 18(12):335-370. 1966.

351. VAJDA, E. Fundamentos da informática. Comentarios sobre o artigo de Pál Gujöre. Tudományos és Müsgaki Tájékostatás (Hungria) 16(4):258267. 1969. (Original não consultado, compendiado de LISA (4):160. 1969).

352. VAN DEN BERG, C. Fryits Donker Duyvis, the fifth pionner. Bibliotheeklaves 53(12):625-633. 1968.

353. VAN DIJK, M. e VAN SLYBE, G. Le service de documentation face a l'explosion de l'information. Paris, Les Editions d'Organisation, 1969. $266 \mathrm{p}$.

354. VARENNES, R. Bibliothéques et bibliothécaires d'aujourd hui et de demain a l'ere electronique. ACBLF Bulletin 15(12):59-66. 1969.

355. VEANER, A. B. The application of computers to library technical processing. College Research Libraries 31(1):36-42. 1970.

356. VERHOEF, M. Librarianship and documentation. UNESCO Bulletin for Libraries 14(5):193-196, 204. 1960.

357. VICENTINI, A. L. C. Bibliothekswissenschaft und Dokumentation. Zentralblatt für Bibliothekswessen 75(1):3-12. 1963.

358. - A dinamização do serviço de informação. Comunicação apresentada à 13 a Reuniấo da Sociedade Brasileira para o Progresso da Ciência. Poços de Caldas, 1961. 10 p.

359. - Informática. Cadernos de Biblioteconomia, Arquivística e Documentação (Portugal) 5(3):83-87. 1968.

Também em húngaro com o título: Informatika. Tudornányos és Müsgaki Tájékoztatás 15(8-9):589-598. 1968.

360. The organization of national documentation and information services in Latin America with a special reference to Brazil. Library Trends 17(3):24-28. 1969.

361. Lydia de Queiroz Sambaquy, bandeirante da documentação da América Latina. Discurso de saudação no Congresso Regional de Documentação da América Latina, 2ํ, Rio de Janeiro, Novembro 23-28, 1969. Sessão solene de encerramento.

362.

. Mecanización y automatización. perspectivas de la América Latina. In Reunión Interamericana de Bibliotecarios y Documentalistas Agrícolas, 2ạ, Bogotá, Diciembre 2-7, 1968, Actas y trabajos presentados. Bogotá, AIBDA, 1968. pp. VD1-VD10.

363. - e OLIVEIRA, E. A. UNIDEK: aplicação a bibliografia brasileira de botânica. In Congresso Regional sôbre Documentação, $2^{\mathrm{a}} \cdot \boldsymbol{\theta}$ Reunião da FID/CLA, 9a, Rio de Janeiro, Novembro 23-28, 1969. Rio de Janeiro, IBBD, 1970. pp. 102-110.

364. VICKERY, B. C. The present state of research into the communication of information. ASLIB Proceedings 15(2):79-91. 1964.

365. VOIGT, O. Dokumentation in entroicklungsgeschichtlicher und informationstheoretischer Sicht. Nachrichten für Dokumentation 19(1-2): 5-10. 1968. 
366. WALDRON, R. K. Implications of technological progress for librarians. College and Research Libraries 19:118-123. 1958.

367. The technology revolution cannot be ignored. PNLA Quarterly 31(3): 216-222. 1967.

368. WASSERMAN, P. The librarian and the machine. Detroit, Gale, 1965. $170 \mathrm{p}$.

369. The library and information professions in a time of change. PNLA Quarterly 31(2):134-145. 1967.

370. WHITEMAN, I. R. New computer languages. International Science and Technology 52:62-68. 1966.

371. WINGER, H. W. Education for area - studies librarianship. Library Quarterly 35(4):361-372. 1965.

372. WOOLSTON, J. E. INIS. UNESCO Bulletin for Libraries 23(3):135-138, 147. 1969.

373. WYSOCKI, A. Problems of the organization of scientific information. Aktualne Problemy Informacji i Dokumentacji (Polônia) 4:4-6. 1964.

374. ZERO-UN. Scope 1968. Annuaire Général de I'Informatique. Versailles 42 rue albert-Joly), 1968 . $62-150 \mathrm{p}$.

\section{SIGLAS UTILIZADAS}

AALS - Association of American Library Schools (Estados Unidos)

ACBLF- Association Canadiene des Bibliothécaires de Langue Française (Canadá)

ADI- American Documentation Institute (Estados Unidos). Desde 1969: American Society for Information Science (ASIS)

AGARD-Advisory Group for Aerospace Research and Development (LUxemburgo)

AIBDA- Asociación Interamericana de Bibliotecarios y Documentalistas Agrícolas (Costa Rica)

AlP - American Institute of Physics (Estados Unidos)

ALA - American Library Association (Estados Unidos)

ANRT- Association Nationale de la Recherche Technique (França)

APLA- Atlantic Provinces Library Association (Estados Unidos)

ASIS- American Society of Information Science (Estados Unidos). Até 1968: American Documentation Institute.

ASLIB- Association of Special Libraries \& Information Bureaux (Inglaterra) BACAP - Bibliografía Agrícola de Centroamérica y Panamá (Projeto)

BAL - Bibliografia Agrícola Latino-americana (AIBDA)

CDU-Classificação Decimal Universal (FID)

CENID- Centro Nacional de Información y Documentación (Chile)

CERDAC-Centro Regional de Documentación Agrícola para América Central (Projeto de UNDP/FAO/IICA)

CETEB - Centro de Ensino Técnico de Brasília (Brasil) 
CIDIA-Centro Interamericano de Documentación e Información Agrícola (Projeto do IICA)

CIUD-Consejo Internacional de las Uniones Científicas, ver tb. ICSU

CLA- Canadian Library Association (Canada)

CLIS - Clearinghouse for Library and Information Sciences (University of Minnesota, Estados Unidos)

COMECON- Comissão Econômica para os Paises Socialistas (URSS)

COMSAT- Committee on Scientific and Technical Communication of NASNAE (Estados Unidos)

CWRU - Case Western Reserve University (Cleveland, Ohio, Estados Unidos) DASP - Departamento Administrativo do Serviço Público (Brasil)

EMAER- Estado-Maior da Aeronáutica (Brasil)

ERIC- Educational Resources Information Center (University of Minnesota, Estados Unidos)

EUDUCOM- Interuniversity Communication Council (Estados Unidos)

FAO- Food \& Agriculture Organization of the United Nations (Itália) (Organização das Naçőes Unidas para a Alimentação e Agricultura)

FIAB - Federação Internacional de Associações de Bibliotecários/ Federación Internacional de Asociaciones de Bibliotecarios (Inglaterra) ver tb. IFLA

FID- Federação Internacional de Documentação/ Féderation Internationale de Documentation/International Federation for Documentation. 7 Hofweg,

The Hague, Netherlands. (Holanda)

FID/CAO- Comissăo da FID para Ásia e Oceânia (Japan)

FID/CCC - Comissão Central de Classificaçăo da FID (Central Classification Committee)

FID/CLA - Comissăo Latino-Americana da FID (Brasil: 1960-1962; Argentina: 1963-1965; Chile: 1966-1969; Brasil: 1969-1972)

FID/CR-Comissão da FID para "Pesquisas em Classificação (Classification Research)

FID/DC - Comissão da FID para "Países em Desenvolvimento" (Developing Countries)

FID/II- Comissão da FID para "Informaçăo para a Indústria". (Information for Industry)

FID/LD- Comissão da FID para "Lingüistica na Documentação" (Linguistics in Documentation)

FID/OM-Comissão da FID para "Sistemas e Técnicas para Operação das Máquinas" (Operational Machine Techniques \& Systems)

FID/RI- Comissão da FID para "Pesquisas sôbre as Bases Teóricas da Informação" (Research on the Theoretical Basis of Information)

FID/TD- Comissão da FID para "Treinamento de Documentalistas" (Training of Documentalists)

FID/TM- Comissão da FID para "Teoria das máquinas e sistemas" (Theory of Machine Technique \& Systems) 
HMSO - Her Majesty's Stationery Office (Inglaterra)

IAALD - International Association of Agricultural Librarians \& Documentalistas (França)

IAEA - International Atomic Energy Agency (Áustria)

IBBD - Instituto Brasileiro de Bibliografia e Documentação (Brasil)

IBM - International Business Machine Corporation (Estados Unidos)

ICFES - Instituto Colombiano de Fomento de la Educación Superior (Colômbia)

ICSU - International Council of Scientific Unions (França). ver tb. CIUC

IFIP - International Federation of Information Processing

IFIS- International Food Information Systems (Inglaterra)

IFLA - International Federation of Library Associations (Inglaterra)

IIB- Institut International de Bibliographie (Bélgica). De 1895 a 1930. De 1931 a 1937: IID. Desde 1938: FID

IICA - Instituto Interamericano de Ciências Agrícolas de la OEA (Costa Rica)

IICA/BSD - Biblioteca y Servicio de Documentación del Instituto Interamericano de Ciências Agrícolas de la OEA (Costa Rica)

IID- Institut Internaional de Documentation (Holanda). De 1931 a 1937. Desde 1938: FID

INE- Instituto Nacional de Estatística (Portugal)

INIS - International Nuclear Information System. (Sistema internacional para informação nuclear) (IAEA, Áustria)

ISA- Information Sciences Abstracts (Estados Unidos)

JCTND - Jugoslovenski Centar za Tehwicku i Naucnu Dokumentaciju (Yugoslavia)

LISA- Library \& Information Science Abstracts (Inglaterra)

NAE - National Academy of Engineering (Estados Unidos)

NAL - National Agricultural Library (Estados Unidos)

NAS - National Academy of Sciences (Estados Unidos)

NATO- North Atlantic Treaty Organization (Luxemburgo). Organização do Tratado do Atlântico Norte (OTAN)

NLL- National Lending Library (Inglaterra)

OCDE- Organization de Cooperation et de Development Economiqués (França) ver tb. OECD

OEA- Organização dos Estados Americanos (Estados Unidos)

OEA/DAC - Departamento de Assuntos Científicos da Organização dos Estados Americanos (Estados Unidos)

OECD - Organization for Economic Cooperation and Development (França) ver tb. OCDE

OTAN - ver NATO

PIDBA - Programa Interamericano de Desarrollo de Bibliotecas Agrícolas (IICA) 
PNUD/80- ver UNDP/80

SLA - Special Libraries Association (Estados Unidos)

TAPPI- Technical Association of Pulp and Paper Industry (Estados Unidos)

UCLA - University of California at Los Angeles (Estados Unidos)

UDC- Universal Decimal Classification ver t. CDU

UNDP/80 - Projeto 80 do Programa de Desenvolvimento das Nações Unidas, com sede no IICA, Turrialba, Costa Rica

UNESCO- United Nations Educational Scientific and Cultural Organization (França) (Organização das Nações Unidas para a Educação, Ciência e Cultura)

UNISIST - UNESCO/ICSU Project on the Feasibility of a World Science Information System (França) Sistema internacional de informação científica, projeto sob os auspícios da UNESCO e do ICSU

UVTEI- Ustredi Vedeckych, Fechnickych a Ekonomickych Informaci (Tchecoslováquia) (Centro de Informação Científica, Técnica e Econômica)

VINITI- Vsesoyuznyi Institut Nauchnoy i Tekhnicheskoy Informatsii (União Soviética) /All Union Institute for Scientific and Technical Information/ Instituto Federal de Informação Científica e Técnica

\section{SUMMARY}

Library means etymologically "care of books". Librarianship is, therefore, the science of library administration. Libraries, royal and sacerdotal privileges during the Ancient Times and Middle Age, became a democratic institution after the 19th Century. As a consequence of scientific and technological progress, books were no longer the only means for knowledge transfer. Librarianship became unadequate and Documentation appeared with Paul Otlet, founder of the International Federation for Documentation (FID), producing the conflict Librarianship versus Documentation. FID established its action dealing with the document as the central part of Documentation. The document, within the new FID programme, looses its roll as the documental unit or as the substance of documentation which is now the information itself. The appearance of the "information science", produces a new conflict Librarianship versus Documentation versus Information Science, and the impact of automation revolution causes a tremendous change in the curricula of library and information sciences schools. Mikhailov and his Russian colleagues from VINITI presented, in 1967, the term INFORMATICS, defending its use. During 1968 and 1969 several new journals and books were published utilizing the word Informatics. Panoramic vision of opinions of librarians, documentalists, philosophers and university professors throughout the world, and a final comparative study of the concepts of Librarianship, Documentation and Informatics, reach a justification and defense of the meaning of this new word as a group of sciences related to the complete study of the information, reflecting its theoretical, applied and social aspects. (Title: From Librarianship to Informatics. Sub-title: Evolution of the documentation concept. Sections: 1) Librarianship, 2) Documentation, 3) Librarianship versus Documentation, 4) Organization of Documentation: FID, 5) Substance of Documentation, 6) Information, 7) Information Science versus Documentation versus Librarianship, 8) Informatics, 9) Conclusions, 10) Bibliographical References (374 citations), and 11) List of used Initials. 
